\title{
Review Article \\ Extracellular Vesicles in Liquid Biopsies: Potential for Disease Diagnosis
}

\author{
Jialing Liu, ${ }^{1}$ Ye Chen, ${ }^{1}$ Fang Pei, ${ }^{1}$ Chongmai Zeng, ${ }^{1}$ Yang Yao, ${ }^{2}$ Wen Liao $\mathbb{D}^{1}$, \\ and Zhihe Zhao ${ }^{1}{ }^{1}$ \\ ${ }^{1}$ Department of Orthodontics, West China Hospital of Stomatology, State Key Laboratory of Oral Diseases \& National Clinical \\ Research Center for Oral Diseases, Sichuan University, Chengdu, China \\ ${ }^{2}$ Department of Implantology, West China Hospital of Stomatology, State Key Laboratory of Oral Diseases \& National Clinical \\ Research Center for Oral Diseases, Sichuan University, Chengdu, China
}

Correspondence should be addressed to Wen Liao; liaowenssw@126.com and Zhihe Zhao; zhzhao@scu.edu.cn

Received 6 October 2020; Revised 19 December 2020; Accepted 23 December 2020; Published 11 January 2021

Academic Editor: Yang Deng

Copyright (c) 2021 Jialing Liu et al. This is an open access article distributed under the Creative Commons Attribution License, which permits unrestricted use, distribution, and reproduction in any medium, provided the original work is properly cited.

Liquid biopsy is conducted through minimally invasive or noninvasive procedures, and the resulting material can be subjected to genomic, proteomic, and lipidomic analyses for early diagnosis of cancers and other diseases. Extracellular vesicles (EVs), one kind of promising tool for liquid biopsy, are nanosized bilayer particles that are secreted by all kinds of cells and that carry cargoes such as lipids, proteins, and nucleic acids, protecting them from enzymatic degradation in the extracellular environment. In this review, we provide a comprehensive introduction to the properties and applications of EVs, including their biogenesis, contents, sample collection, isolation, and applications in diagnostics based on liquid biopsy.

\section{Introduction}

Liquid biopsy is conducted through minimally invasive or noninvasive procedures, the samples are simple to store, and they can be processed fast enough to provide realtime information. The term "liquid biopsy" is derived from the term "tissue biopsy." Tissue biopsies, in contrast, are quite invasive, involving the risk of complications, and cannot provide real-time information [1]. In addition, the insights from tissue biopsies may be biased because they reflect the state of only one part of the tissue. Liquid biopsies contain numerous potential cells or particles that could be analyzed: extracellular vesicles (EVs), circulating tumor DNA, circulating tumor cells, circulating endothelial cells, and cell-free fetal DNA [2]. Among these components of liquid biopsies, EVs have attracted researchers' interest because they have advantages over other analytes, such as stability in the circulation.

EVs are lipid bilayer-enclosed particles released from all types of cells and found in biological fluids such as blood, cerebrospinal fluid (CSF), urine, saliva, breast milk, seminal fluid, and tears [3, 4]. EVs were first reported in 1946 by Chargaff and West after they ultracentrifuged blood plasma and obtained particles with procoagulant properties [5]. In 1967, Wolf reported that this coagulant material in highspeed supernatants originated from platelets and named it "platelet dust" [6]. This "dust" did not attract much attention until the 21st century after EVs were identified as potential vehicles to transfer signaling molecules from cell to cell. Since then, research has revealed three main classes of EVs: microvesicles, exosomes, and apoptotic bodies [7]. Microvesicles are directly created by outward budding of the plasma membrane (PM), while exosomes originate from intraluminal vesicles produced by inward budding [8]. Apoptotic bodies arise when cells undergo apoptosis, and they are not covered in the present review (Figure 1). EVs are an attractive liquid biopsy tool as they contain proteins, lipids, and nucleic acids from their parental cells, which may be tumor cells or other types of diseased cells, and they can sensitively reflect an individual's health status $[9,10]$. 


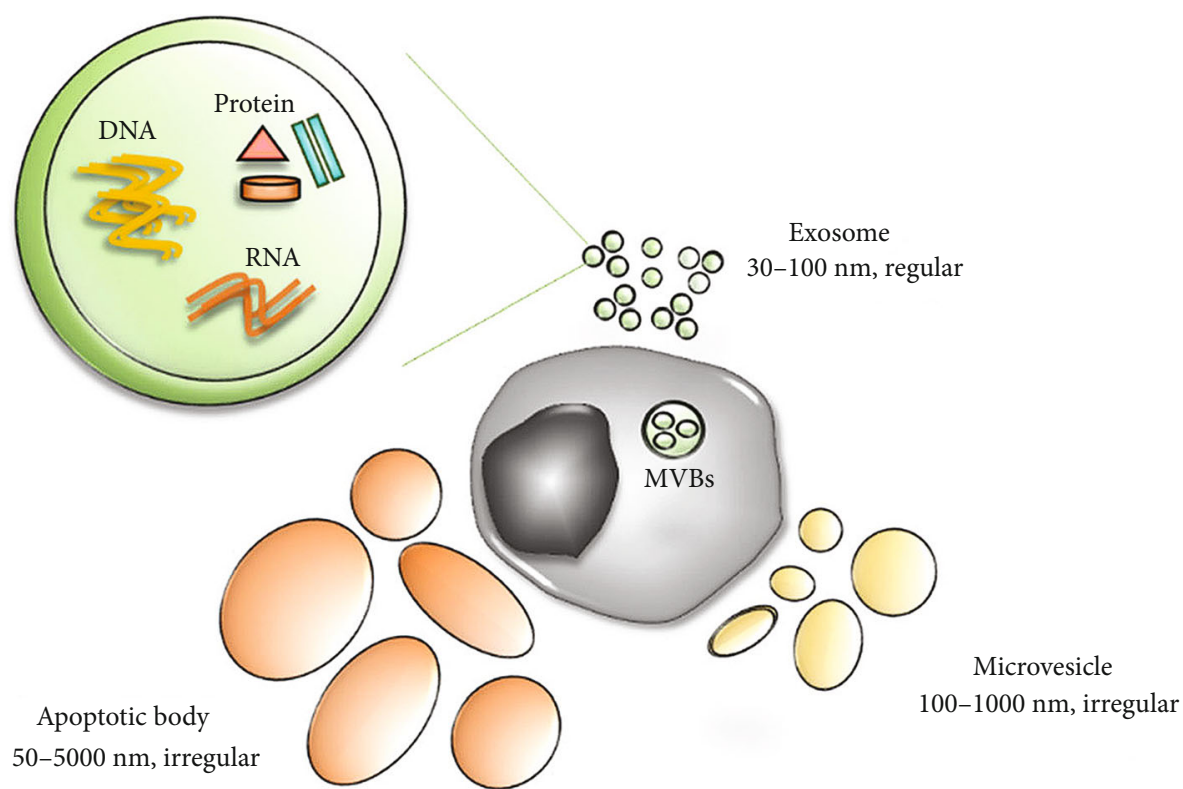

Figure 1: Three main classes of extracellular vesicles: microvesicles, exosomes, and apoptotic bodies. Reprinted from Kim et al. [195].

It is worth pointing out that membranous EVs and molecules entrapped and enclosed in EVs show good stability in both morphology and chemical property. The lipid bilayer surrounding EVs protects the biocargo from extracellular proteases and other enzymes. For example, one study suggested that phosphoproteins could be recovered from EVs isolated from plasma that had remained frozen longer than five years [11]. Similarly, another study found that storing EVs at $20^{\circ} \mathrm{C}$ or subjecting them to multiple rounds of ultracentrifugation did not substantially alter their size [12]. Luminal protein TSG101 has been shown to remain quite stable within EVs [13], so do DNA [14], microRNAs (miRNAs) [15], and circular RNAs (circRNAs) [16]. The stability of EVs and their contents makes them promising biomarkers.

In this review, we summarize the biogenesis and contents of EVs as well as their isolation techniques from biological fluids. From our point of view, EVs are promising tools for liquid biopsy, especially for diagnoses based on the proteins, nucleic acids, and lipids within the EVs.

\section{Biogenesis and Contents of EVs}

2.1. Biogenesis of EVs. All cells are able to release EVs, including exosomes, into the extracellular space [17]. The biogenesis of exosomes is as follows. First, the PM invaginates to produce a cup-shaped structure containing fluid, lipids, proteins, metabolites from the extracellular milieu, and cell surface proteins. This inward budding or endocytosis generates early-sorting endosomes, which mature into late-sorting endosomes. Next, intraluminal vesicles are generated and accumulate in late-sorting endosomes. Cytoplasmic constituents enter the intraluminal vesicles and ultimately become the cargo of the future exosomes. Late-sorting endosomes containing intraluminal vesicles give rise to multivesicular bodies.
In most cells, multivesicular bodies fuse with autophagosomes or lysosomes, and the contents are ultimately degraded by lysosomal hydrolases. However, multivesicular bodies bearing markers such as lysosome-associated membrane proteins LAMP1/LAMP2, the tetraspanin CD63, or other molecules can be transported to the PM, where they release their contents into the extracellular milieu $[17,18]$. In this way, exosomes encapsulate substances from the parental cells.

This process of exosome biogenesis is regulated by mechanisms dependent on endosomal sorting complexes required for transport (ESCRT), as well as by ESCRT-independent mechanisms. The ESCRT machinery is an evolutionarily conserved membrane remodeling complex that participates in a broad range of physiological and pathophysiological processes such as biogenesis of exosomes and release of envelope retroviruses [19]. The ESCRT machinery is composed of nearly 30 proteins that assemble into four complexes. Among them, ESCRT-0, ESCRT-I, and ESCRT-II are stable polymers, whereas ESCRT-III forms through the dynamic assembly of monomeric proteins [20]. The ESCRT-0 complex, which can recognize and cluster ubiquitinated transmembrane proteins, is a heterodimer made up of signaling transducing adaptor molecule (STAM) and hepatocyte growth factor-regulated tyrosine kinase substrate (HRS). ESCRT-I is instrumental for inducing membrane budding and sorting cargoes into multivesicular bodies. ESCRT-III is dominant in driving membrane scission. ESCRT-I and ESCRT-III are connected by ESCRT-II, which is a heterotetramer consisting of four vacuolar protein sorting- (VPS-) associated proteins (one VPS22, one VPS36, and two VPS25) [21, 22].

Exosomes can also be formed in the absence of ESCRT complexes, which is called the ESCRT-independent mechanism. In experiments involving mouse oligodendroglial cells that can secrete proteolipid protein- (PLP-) containing exosomes, knockdown of HRS, Alix, or TSG101 to block 
the generation of ESCRT machinery components did not affect inward budding of PLP [23]. Budding was, however, blocked by the neutral sphingomyelinase inhibitor, which inhibits the formation of ceramide in exosomes. These results led to the discovery of ceramide-triggered budding of exosome-associated domains into multivesicular endosomes. Several membrane proteins of the tetraspanin family, such as CD63, CD9, CD81, and CD82, have been implicated in the sorting of cargoes and the formation of exosomes [24].

In contrast to exosomes, microvesicles form through outward budding from certain microdomains in the PM, especially microdomains enriched in cholesterol and sphingolipids [25]. Changes in the $\mathrm{Ca}^{2+}$ level and in the composition of lipid and protein within the PM have been implicated in the shedding of microvesicles into the extracellular space. These changes are driven by enzyme machines, including scramblases, calpain, and aminophospholipid translocases such as flippases and floppases, which favor the flopping of phosphatidylserine (PS) from the interior to exterior membrane leaflets [26]. The flopping of PS results in bending of the PM, restructuring of the underlying cytoskeleton, and biogenesis of microvesicles. However, microvesicle biogenesis can also proceed without the flopping of PS, which suggests that other lipids also contribute to the budding of microvesicles [27]. The PM and cytoskeleton are tightly connected, and cytoskeletal changes are associated with the biogenesis of microvesicles. Thus, cytoskeletal elements and their regulators are considered to contribute to microvesicle biogenesis [28]. Actin is perhaps one of the best-studied cytoskeletal elements. $\beta$ - and $\gamma$-cytoplasmic actins facilitate endothelial microvesicle formation [29]. The ras homolog family member A (Rho A) is a classical Rho GTPase that regulates cytoskeleton function, especially actin stress fiber formation. It is not surprising, then, that a Rho A-associated signaling pathway has been implicated in the generation of microvesicles (Figure 2) [30]. The biogenesis of EVs is quite complex and is still being elucidated, and scientists are still on the way of exploration.

2.2. Biomolecules Contained in EVs. EVs contain heterogeneous contents from their cells of origin, including proteins, miRNAs, messenger RNAs (mRNAs), circRNAs, DNA, and lipids, potentially offering a complete range of biomolecules for assessing the original cell's health or disease condition.

The range of the EV biocargo so far reported in the literature has been cataloged in EVpedia (http://evpedia.info), Vesiclepedia (http://www.microvesicles.org), and ExoCarta (http://www.exocarta.org) [31-33]. A range of analytical techniques can extract valuable information from the heterogeneous EV biocargo (Figure 3). These techniques include SDS-PAGE, western blotting, enzyme-linked immunosorbent assay, flow cytometry, microfluidic assays, and mass spectrometry- (MS-) based proteomic analysis, all of which are used for protein analysis; nucleic acid sequencing, which is applied for nucleic acid analysis; and liquid chromatography and gas chromatography coupled to MS (LC-MS and GCMS), which are able to analyze lipid species in EVs [34-36].
2.2.1. Proteins. Thousands of proteins, cytosolic and membrane-bound, have been found in EVs. Proteins traditionally used to identify EVs are CD9, CD63, CD81, annexins, ESCRT proteins, and TSG101 [37], all of which participate in vesicle sorting and trafficking. Proteins in EVs have attracted substantial attention as disease biomarkers. Assaying tumor-derived proteins directly from body fluids lacks sensitivity because the proteins have been diluted and degraded, but assaying proteins in tumor-derived EVs can work much better because the proteins are locally concentrated and protected within the vesicles [38]. For example, programmed death-ligand 1 (PD-L1) protein in exosomes may be a biomarker for metastatic melanoma, non-smallcell lung cancer, and head and neck squamous cell carcinoma [39-41]. Glypican-1 in exosomes may be a biomarker for pancreatic, colorectal, and breast cancers [42-44]. EVresident diagnostic biomarker proteins may include DEL-1 [45], MIF [46], and CEA [47].

2.2.2. Nucleic Acids. In 2007, Valadi and coworkers discovered that exosomes contain mRNAs and miRNAs that can be transferred to recipient cells, where they can function [48]. Intriguingly, many exosomal miRNAs and mRNAs are not detectable in body fluids, suggesting that they may be highly specific noninvasive biomarkers. For example, small RNA sequencing of exosomes from the plasma of patients with papillary thyroid cancer identified miR-485$3 p$ and miR-4433a-5p as potential diagnostic biomarkers [49]. Levels of exosomal miR-485-3p differed between patients at low or high risk of illness. Levels of the mRNA encoding chemokine (C-C motif) ligand (CCL2) in urinary exosomes may reflect the severity of IgA nephropathy [50], which is the most common primary glomerular disease and the primary driver of end-stage kidney disease $[51,52]$.

Before 2014, EVs had been reported to contain only ssDNA and mitochondrial DNA. Subsequently, they were also found to contain dsDNA; in fact, they were found to contain material from all chromosomes, potentially providing an extremely detailed picture of the genetic makeup of the parental cells, including the presence of mutations [53, 54]. For example, DNA analysis of exosomes from cultures of non-small-cell lung cancer cells has detected mutations in epidermal growth factor receptor [54], and DNA analysis of exosomes from the serum of pancreatic cancer patients has detected mutations in KRAS and p53 [53].

2.2.3. Lipids. Compared with their parental cells, which are enriched in phosphatidylcholine, EVs are generally enriched in phosphatidylserine, cholesterol, sphingomyelin, and glycosphingolipids. The ratios of EVs versus those of parental cells are about 2.1 (sphingomyelin and phosphatidylserine) and 1.4 (cholesterol) [55]. The lipid composition of EVs can be studied in detail using mass spectrometry, highperformance liquid chromatography, nuclear magnetic resonance, gas chromatography-mass spectrometry, and computational approaches [56-62]. One study identified differences in lipid composition between EVs of ovarian cancer cells and ovarian epithelial cells, and these differences may facilitate early diagnosis [63]. Another study found that 


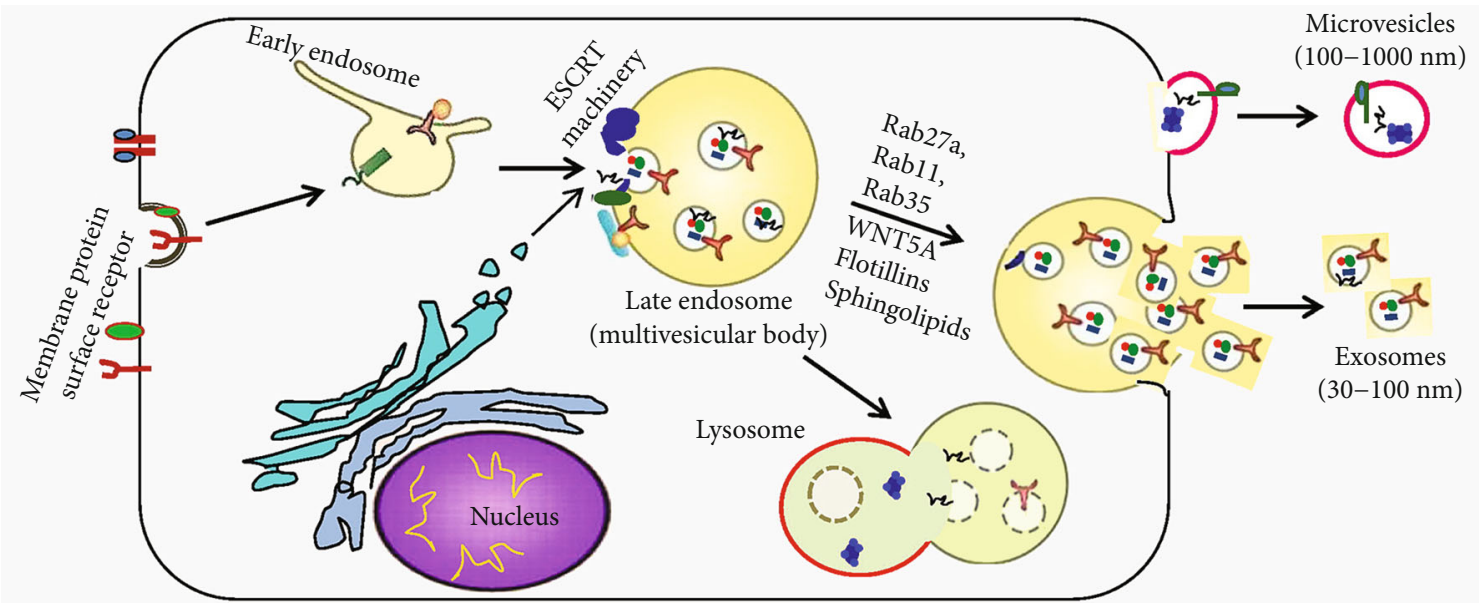

FIGURE 2: Schematic depiction of biogenesis of exosomes and microvesicles, two types of extracellular vesicles. Reprinted from Ailawadi et al. [196].

analysis of exosomal lipids was able to distinguish non-smallcell lung cancer in the early or late stages [64]. A third study identified nine lipid species, including PS and lactosylceramide, whose levels differed significantly between prostate cancer patients and healthy controls [65].

\section{Sample Collection before Isolation of EVs}

EVs are intercellular shuttles released by most cells, and they can be found in nearly all body fluids [66]. Different body fluids have different characteristics, such as density and viscosity, as well as different compositions. For example, blood is denser and more viscous than urine. Urine contains creatinine, urea, and uric acid, while saliva contains amylase and lipase. Therefore, these different fluids should be collected and processed in different ways in order to isolate EVs. Three kinds of body fluids commonly used for harvesting EVs are described.

3.1. Blood (Plasma/Serum). Plasma and serum are blood cellfree fractions obtained through centrifugation. A global survey of members of the International Society for Extracellular Vesicles indicated that $47 \%$ of respondents isolated their EVs from plasma and 22\% from serum [67]. The efficiency of EV isolation can depend on numerous factors linked to the quality of the blood sample, including donor age, medical history, diet, time of sample collection, choice of anticoagulant, and venipuncture [68-70]. In fact, the physical forces during blood drawing can activate platelets and trigger the release of platelet-derived EVs, altering the quality of the blood samples. Therefore, venipuncture should preferably be conducted from the same site using a nonbutterfly needle of gauge 21 or larger $[71,72]$. The most suitable anticoagulant depends on the downstream analyses to be conducted. For instance, heparin is not recommended if the samples will subsequently be analyzed using PCR because it can competitively inhibit the binding of primers and enzymes to the nucleic acid template [73]. Alternatives include citrate-theophylline-adenosine-dipyridamole (CTAD), citrate, ethyl- enediaminetetraacetic acid, and sodium fluoride/potassium oxalate. CTAD inhibits platelet activation [74], and adding it to EDTA can reduce platelet clumping [75]. In 2012, the International Society on Thrombosis and Haemostasis recommended citrate as the anticoagulant for EV studies, and it is currently in wide use [76].

3.2. Urine. Urine is a metabolic by-product flowing from the kidney to the bladder. Urinary EVs are quite stable, and their biomolecular cargo is protected from the ribonucleases, proteases, and lipases in urine [77]. Sampling urine is less invasive than sampling blood, and the miRNA content of urinary EVs correlates with that of serum EVs [78]. Therefore, urine is extremely attractive as a source of EVs. Isolating intact EVs from urine is a challenge because of the high concentration of Tamm-Horsfall protein (THP), also known as uromodulin, which is the most abundant glycoprotein in urine [79]. THP can trap EVs to form filamentous networks, interfering with EV isolation. Adding dithiothreitol can reduce disulfide bonds linking the THP monomers, not only releasing the entrapped EVs but also potentially altering the structure of proteins of interest [80]. The detergent 3-[(3cholamidopropyl)dimethylammonio]-1-propanesulfonate (CHAPS) may be superior to dithiothreitol because it can reduce THP interference without altering EV morphology or exosomal marker distribution, but the method is timeconsuming [81]. In another lengthy procedure, raising the $\mathrm{pH}$ and reducing ionic strength can also disrupt the association between THP and EVs [82]. A faster method that can preserve the structure of proteins of interest may be hydrostatic filtration dialysis, combined with urea denaturation and depolymerization of THP [79].

3.3. Saliva. Saliva is a physiological fluid produced and secreted by salivary glands, comprising minor salivary glands and three major glands (submandibular, parotid, and sublingual). It plays a vital role in lubrication, digestion, and mastication, and it is the first line of defense against pathogens, as it contains various immunoglobulins and enzymes. A healthy 


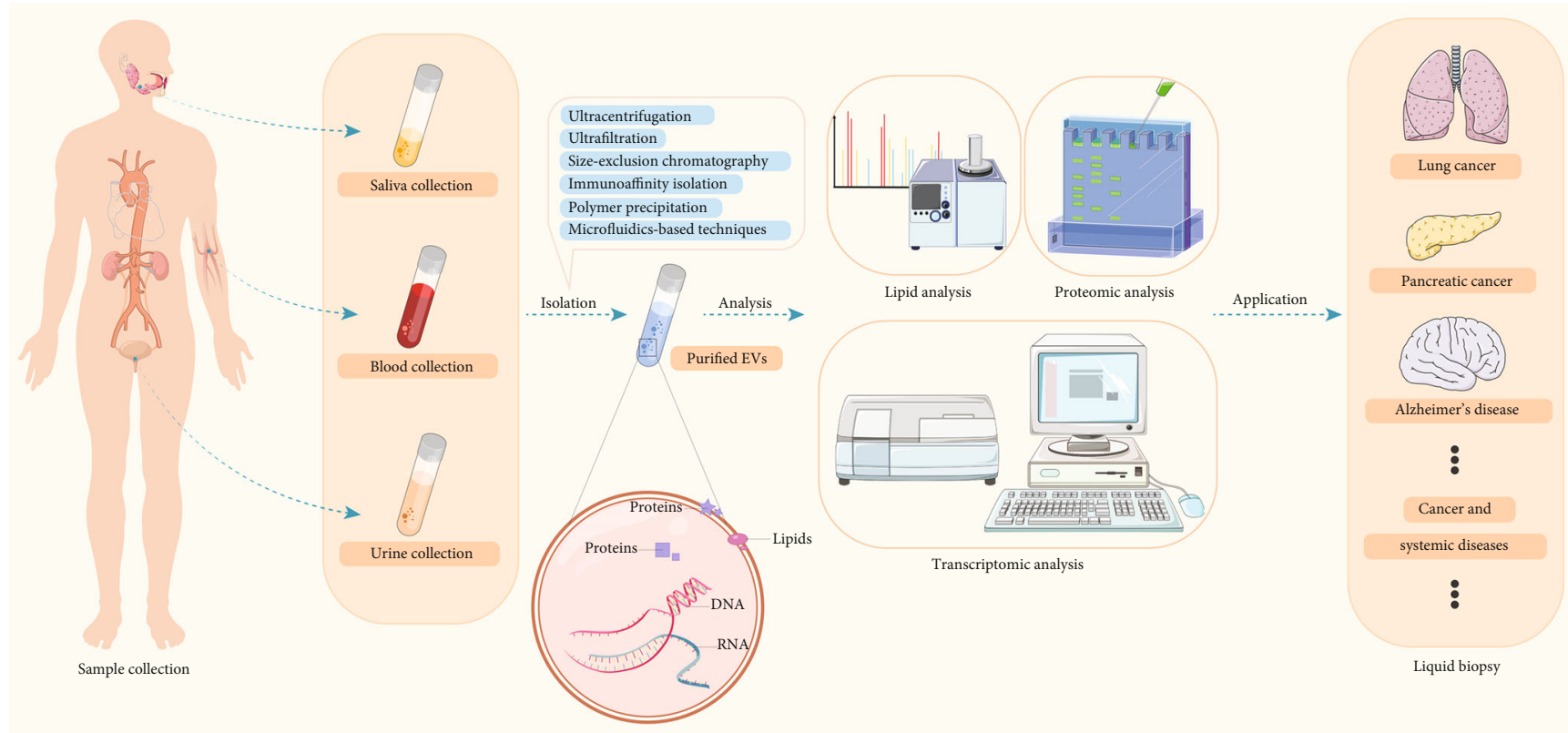

Figure 3: Different methods to isolate extracellular vesicles. Reprinted from Pang et al. [93].

individual secretes $600 \mathrm{ml}$ of saliva per day, so obtaining adequate saliva samples is usually straightforward. The quality of EVs isolated from saliva can depend on numerous factors that affect the quality of the saliva sample, including the timing and location of sampling $[70,83,84]$, as well as the technique of sample collection [85], which can be through passive drooling [86] or stimulation by chewing or administration of a chemical [87]. Concentrations of salivary tissue factors [88] and cortisol [89] follow a circadian rhythm, which can affect the isolation and analysis of EVs. It may be better to collect saliva only from the parotid gland [90]. Eating, drinking, smoking, and exercising can affect saliva content [91], so individuals should smoke and drink in moderation as well as avoid exercise before sample collection. They should refrain from eating for one hour before collection.

\section{Isolation of EVs}

Many studies have examined the diagnostic potential of EVs, but their clinical application is limited by the lack of simple, efficient procedures to obtain EVs with high purity. Six major isolation strategies have been published, each with its own advantages and limitations, including ultracentrifugation, polymer precipitation, ultrafiltration, size-exclusion chromatography, affinity isolation, and microfluidics-based techniques (Figure 4) $[92,93]$.

4.1. Ultracentrifugation. Ultracentrifugation methods, namely, differential ultracentrifugation or density gradient centrifugation, are usually applied to isolate EVs from biofluids [70] (Figure 4(a)). Differential ultracentrifugation is regarded as the gold standard for EV isolation [67] and is based on the fact that the centrifugal force pulls larger and denser particles into the pellet [94]. This isolation method, although relatively simple and cheap, leads to EVs that can be contaminated with protein aggregates, especially when the starting sample is serum or plasma, and it requires large initial volumes [95].

A more effective variation of this method is density gradient ultracentrifugation, which involves ultracentrifugation through a density gradient. This method can lead to higher $\mathrm{EV}$ yield and lower protein contamination than conventional differential ultracentrifugation [95]. Similar to differential ultracentrifugation, the principle of density gradient centrifugation is also based on the size, shape, mass, and density of EVs. As an example of applying this method, the body fluid sample is placed at the top of a density gradient with density decreasing from the bottom to the top in a centrifuge tube. The density gradient is typically iodixanol or sucrose. The application of a centrifugal force causes the solutes in the sample to move through the gradient at a characteristic sedimentation rate, allowing different components to separate from one another. Density gradient ultracentrifugation is increasingly popular as it leads to higher EV yield and lower protein contamination than differential ultracentrifugation [95]. The combination of two types of density gradient ultracentrifugation, namely, coupling rate-zonal centrifugation or isopycnic-zonal centrifugation, with differential ultracentrifugation, may lead to EVs of higher purity [96]. The drawback of this combination method is it requires additional preparation, time, and cost.

4.2. Size-Based Techniques. Isolation of EVs can be performed using ultrafiltration, which is a size-based isolation technique consisting of semipermeable membrane filtration (Figure 4(c)). This separation process is usually used for purifying and concentrating protein solutions, and later, it was found to be effective in isolating EVs. Larger particles such as EVs are retained by the filter, while smaller particles pass through [97]. This approach is faster and easier than 


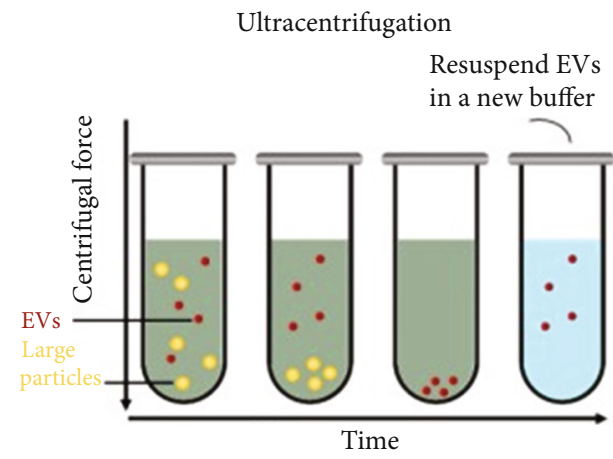

(a)

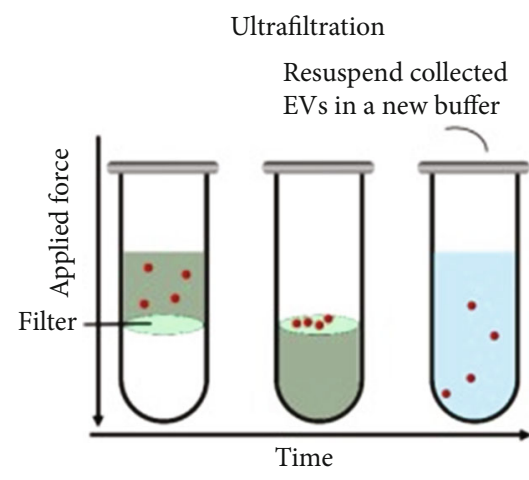

(c)

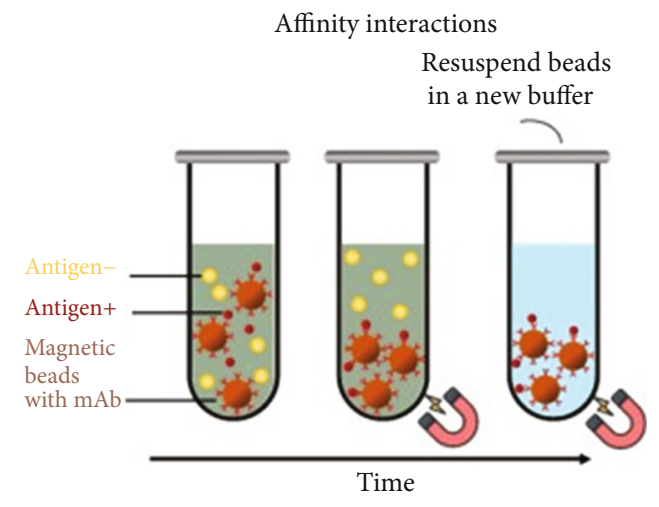

(e)

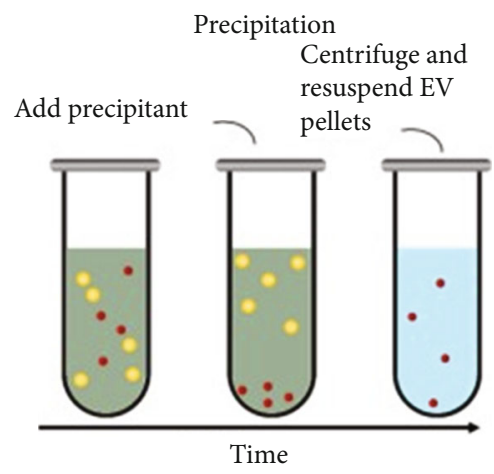

(b)

Size-exclusion chromatography

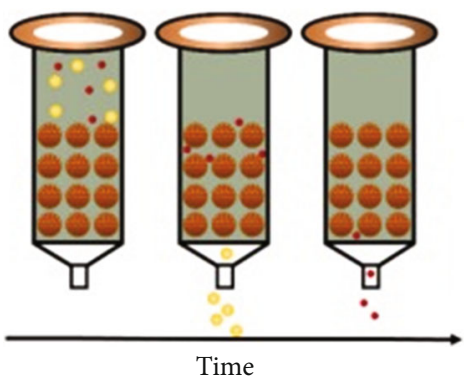

(d)

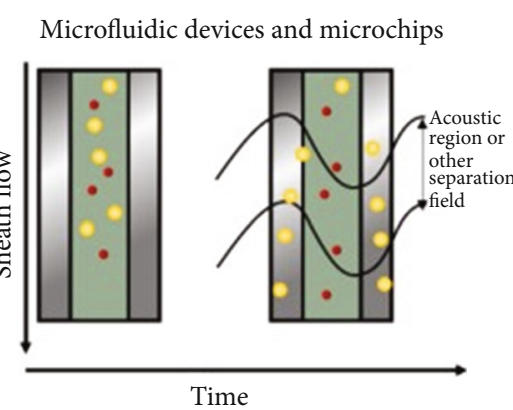

(f)

FiguRE 4: Schematic representation of the analysis of extracellular vesicles in liquid biopsies for clinical medicine.

ultracentrifugation, and a relatively small sample can provide adequate material, such as $0.5 \mathrm{ml}$ urine [98]. However, "cakes" can form on the filter and block it, and EVs can deform at the filter interface as a result of pulling forces. To solve this problem, in 2018, Busatto et al. invented a novel size-based filtration method named tangential flow filtration [99], which is gentler and can avoid filter clogging, resulting in higher yield. Commercially available kits have been developed that rely on size-based isolation. In these kits, the sample is forced through two membranes, a $200 \mathrm{~nm}$ membrane at the top and a $20 \mathrm{~nm}$ membrane at the bottom. The lower membrane captures EVs $<200 \mathrm{~nm}$ or $>20 \mathrm{~nm}$, while larger vesicles are retained on the upper filter, and the smallest vesicles are discarded [100]. Size-exclusion chromatography also isolates EVs by size: smaller molecules slow down because they enter the pores of the gel, while EVs do not enter the pores and flow through faster [101] (Figure 4(d)). This technique can preserve EV structure better than ultracentrifugation and ultrafiltration. However, it cannot effectively separate EVs from similarly sized lipoproteins or protein aggregates.

4.3. Immunoaffinity Isolation and Other Methods. Immunoaffinity isolation is based on the presence of surface proteins or antigens on the EV membrane: antibodies are used to bind these antigens and thereby isolate the desired EV subpopulation (Figure 4(e)). The antibodies can be attached to magnetic beads, culture dishes, resins, and other substrates. For instance, melanoma-derived exosomes have been captured from plasma using magnetic beads carrying the anti-CSPG4 
monoclonal antibody [102]. Many proteins have been explored as biomarkers for capturing EVs, including CD63, CD34, and CD326. Some researchers have suggested that CD63 lacks adequate specificity, leading them to develop an immunoaffinity-based microfluidic isolation device called the ${ }^{\text {new }}$ ExoChip with higher specificity of EV isolation [103]. An enzyme-linked immunosorbent assay has also been introduced to isolate EVs, in which the antibody is immobilized on a microplate [104]. This method can isolate EVs from plasma, serum, and urine samples as small as $100 \mu \mathrm{l}$. While immunoaffinity capture allows the isolation of specific EV subsets, current methods cannot exploit intracellular antigens. Another problem is that the EVs eluted from magnetic beads can lose some of their activity. Immunoaffinity methods are expensive, and yields of purified EVs are low. There is another isolation method called polymer precipitation, whose principle is that a hydrophilic polymer or reagent is added to the sample, and the polymer interacts with water surrounding the EVs, causing them to precipitate (Figure 4(b)). This method is rapid and provides a high yield [105], but EV purity can be low because the polymer precipitates not only EVs but also any water-soluble material, including lipoproteins and nucleic acids [106, 107].

Although the above-listed methods could be applied for EV isolation, only microfluidics-based techniques can combine $\mathrm{EV}$ isolation and disease detection in one platform (Figure 4(f)). They offer portability, fast isolation, cost-efficiency, and small starting volume. Size-based microfluidics use nanowire and micropillar structures to separate EVs with diameters in a certain range from smaller cellular debris, proteins, and other particles [108]. This technique can isolate various subtypes of EVs and minimize contamination by proteins and other nanoparticles, but it requires complicated photolithography fabrication, saturation limits are relatively low, and recovery is slow. Immunoaffinity-based microfluidics separates EVs through the interaction of surface or intravesicular EV biomarkers with antibodies immobilized onto the microchannel surface or magnetic beads. Dynamic exosome microfluidics utilizes an electrical or acoustic field to separate EVs from other nanoparticles [109]. By changing field magnitude and frequency, this technique can separate EV subtypes without the need for complicated photolithography fabrication.

\section{Diagnosis of Disease Based on Analysis of EVs in Liquid Biopsies}

Exploring diagnostic methods based on the analysis of contents in biofluids has become a hot research topic in recent years. Because EVs are stable and carry diverse cargo molecules, they are considered a promising tool for noninvasive diagnosis. Most studies of liquid biopsy have focused on cancer, especially lung cancer. The first important milestone in liquid biopsy came in 2016 when the US Food and Drug Administration approved the first diagnostic test for lung cancer based on circulating tumor DNA in blood samples [110]. Studies have also examined EVs in other diseases, such as severe interstitial fibrosis and tubular atrophy in postrenal transplantation [111].
Plasma and serum samples are the most frequent forms of liquid biopsies from which EVs are purified, but EVs isolated from urine and saliva can also be clinically useful (Figure 3). Contents of EVs can depend on the biofluids from which they were isolated [78]. The differences of RNA profiles of EVs isolated from serum and urine of patients with cholangiocarcinoma were reported, indicating that for certain diseases, EVs purified from urine may provide differential diagnostic accuracy compared with EVs from blood [112]. In patients with diabetic kidney disease, their miRNAs from urinary and serum EVs show moderate to strong correlations with each other [78], but further work is needed to determine whether one type of sample is better for clinical analyses. In patients with lung cancer, the proteomes of exosomes were found to differ between saliva and serum [113]. Based on the fact that EVs isolated from specific biofluids may provide specific diagnostic information for certain diseases, we described diseases according to the classification of biofluids (blood, urine, or saliva). Table 1 summarizes typical examples of EV contents that may serve as biomarkers.

\subsection{Blood (Plasma/Serum)}

5.1.1. Blood-Based Liquid Biopsy in Cancer. Non-small-cell lung cancer, breast cancer, pancreatic cancer, colorectal cancer, ovarian cancer, and nasopharyngeal carcinoma can be detected on the basis of blood-derived EVs. Non-small-cell lung cancer, a subtype of lung cancer, is the leading cause of cancer-associated mortality worldwide [114]. Proteins and miRNAs within blood-derived EVs can aid in diagnosis; such proteins include epidermal growth factor receptor, NYESO-1, PLAP, EpCAM, and Alix [115], as well as fibronectin [116]. In addition, levels of alpha-2-HS glycoprotein and extracellular matrix protein 1 in serum EVs are significantly higher in patients than in healthy controls, suggesting diagnostic potential [117]. Potentially diagnostic EV-derived nucleic acids include the long noncoding RNA called growth arrest-specific transcript 5, whose levels in serum EVs are significantly lower in patients than in healthy controls [118]. It has been suggested that a single biomarker detection is not fully adequate, and combining miRNA and protein markers may be particularly effective at diagnosing non-small-cell lung cancer. One combination may be miR-17-5p, cytokeratin 19 fragment, carcinoembryonic antigen, and squamous cell carcinoma antigen, which in one study showed an area under the receiver operating characteristic curve of 0.860 during training and 0.844 during validation [119].

Breast cancer, which affects the mammary gland epithelium, is the most common malignancy affecting women, and it can rapidly metastasize to the lymph and blood [120]. Since early detection can substantially improve prognosis, its diagnosis based on liquid biopsy has received much attention. High-throughput sequencing of small RNAs in EVs from nine breast cancer cell lines indicated a different profile between this cancer and other types of cancer [121], suggesting the diagnostic potential of small RNAs. For example, levels of miR-1246 and miR-21 in plasma EVs are significantly higher in breast cancer patients than in controls [122], 
TABLE 1: Examples of potential biomarkers from extracellular vesicles.

\begin{tabular}{|c|c|c|c|c|}
\hline $\begin{array}{l}\text { Body } \\
\text { fluid }\end{array}$ & Disease & Proteins and fatty acids & Nucleic acids & References \\
\hline \multirow{10}{*}{ Blood } & $\begin{array}{l}\text { Non-small-cell lung } \\
\text { cancer }\end{array}$ & $\begin{array}{l}\text { EGFR, NY-ESO-1, PLAP, EpCAM, Alix, } \\
\text { fibronectin, AHSG, and ECM1 }\end{array}$ & $\begin{array}{c}\text { GAS5, miR-17-5p, cytokeratin } 19 \text { fragment, } \\
\text { carcinoembryonic antigen, and squamous } \\
\text { cell carcinoma antigen }\end{array}$ & $117-121$ \\
\hline & Breast cancer & $\begin{array}{c}\text { HER2, CD47, DEL-1, EpCAM, PKG1, NFX1, } \\
\text { RALGAPA2, TJP2 }\end{array}$ & miR-1246, miR-21, miR-233-3p & $\begin{array}{c}11,124- \\
127\end{array}$ \\
\hline & Pancreatic cancer & $\begin{array}{l}\text { Glypican-1, CD44v6, Tspan8, } \\
\text { GPC1, EpCAM, MET, CD104, } \\
\text { CD82, LysoPC 22:0 }\end{array}$ & $\begin{array}{l}\text { miR-17-5p, miR-21, miR-1246, miR-4644, } \\
\text { miR-3976, miR-4306 }\end{array}$ & $\begin{array}{c}45,46 \\
128-130\end{array}$ \\
\hline & Colorectal cancer & CD147 & $\begin{array}{l}\text { let-7a, miR-1229, miR-1246, miR-150, } \\
\text { miR-21, miR-223, miR-23a }\end{array}$ & 131,132 \\
\hline & Ovarian cancer & Claudin-4, cholesterol ester, zymosterol & $\begin{array}{l}\text { miR-21, miR-141, miR-200a, miR-200b, } \\
\text { miR-200c, miR-203, miR-205, miR-214 }\end{array}$ & $\begin{array}{c}65,133 \\
134\end{array}$ \\
\hline & $\begin{array}{l}\text { Nasopharyngeal } \\
\text { carcinoma }\end{array}$ & Galectin-9 & BART7-3p, BART9-3p, BART17, BART13-3p & $137-140$ \\
\hline & Alzheimer's disease & Neurogranin & Unknown & 142 \\
\hline & Parkinson's disease & $\alpha$-Synuclein & Unknown & 144 \\
\hline & $\begin{array}{l}\text { Coronary artery } \\
\text { disease }\end{array}$ & Unknown & SOCS2-AS1 & 145 \\
\hline & $\begin{array}{l}\text { Acute myocardial } \\
\text { infarction }\end{array}$ & Unknown & miR-1915-3p, miR-4507, miR-3656, miR-183 & 146 \\
\hline \multirow{6}{*}{ Urine } & Prostate cancer & $\begin{array}{l}\text { FABP5, TGM4, ADSV, Flotilin2, } \\
\text { PARK7, phosphatidylserine }(18: 1 / 18: 1) \text {, } \\
\text { lactosylceramide (d18:1/16:0) }\end{array}$ & miR-196a-5p, miR-501-3p, miR-2909 & $\begin{array}{c}67,149- \\
153\end{array}$ \\
\hline & Bladder cancer & $\begin{array}{c}\alpha 1 \text {-antitrypsin, H2B1K, TALDO1, EPS8, } \\
\text { CEAM5 }\end{array}$ & MALAT1, PCAT-1, SPRY4-IT1 & $\begin{array}{l}158-159 \\
161\end{array}$ \\
\hline & Renal cell carcinoma & $\begin{array}{c}\text { CP, PODXL, CD10, MMP9, EMMPRIN, } \\
\text { CAIX, DPEP1, DKK4, Synten-in1, and AQP1 }\end{array}$ & miR-126-3p, miR-449a, miR-34b-5p & $164-165$ \\
\hline & Diabetic nephropathy & C-megalin, Elf3, WT1 & mRNA WT1 & $168-171$ \\
\hline & Lupus nephritis & Unknown & let-7a, miR-21, miR-21, miR-150, miR-29c & $173-174$ \\
\hline & Alzheimer's disease & $\mathrm{A} \beta 1-42, \mathrm{P}-\mathrm{S} 396-\mathrm{tau}$ & Unknown & 175 \\
\hline \multirow{11}{*}{ Saliva } & $\begin{array}{l}\text { Oral squamous cell } \\
\text { carcinoma }\end{array}$ & CD63, CD81, CD9 & $\begin{array}{l}\text { miR-517b-3p, miR-302b-3p, miR-412-3p, } \\
\text { miR-512-3p, miR-24-3p }\end{array}$ & $177-179$ \\
\hline & Lung cancer & BPIFA1, CRNN, MUC5B, IQGAP & Unknown & 181 \\
\hline & Melanoma & Unknown & Melan-A RNA & 182 \\
\hline & $\begin{array}{c}\text { Pancreatobiliary tract } \\
\text { cancer }\end{array}$ & Unknown & miR-1246, miR-4644 & 183 \\
\hline & Pancreatic cancer & Unknown & $\begin{array}{l}\text { Apbb1ip, Daf2, Foxp1, Incenp, Aspn, } \\
\text { BC031781, Gng2 mRNA }\end{array}$ & 184 \\
\hline & $\begin{array}{l}\text { Head and neck } \\
\text { squamous cell } \\
\text { carcinoma }\end{array}$ & Unknown & miR-486-5p, miR-10b-5p, miR-486-3p & $185-186$ \\
\hline & Oral lichen planus & Unknown & miR-4484 & 187 \\
\hline & Periodontitis & Unknown & PD-L1 mRNA & 188 \\
\hline & Sjögren's syndrome & GNA13, APMAP, WDR1, LSP1, SIRPA & Unknown & 191 \\
\hline & $\begin{array}{l}\text { Inflammatory bowel } \\
\text { disease }\end{array}$ & PSMA7 & Unknown & 192 \\
\hline & Aging process & Unknown & $\operatorname{miR}-24-3 p$ & 193 \\
\hline
\end{tabular}

and levels of miR-233-3p in EVs have been associated with the degree of malignancy [123]. In addition to small RNAs, several proteins from EVs show diagnostic potential, such as HER2, CD47, DEL-1, and EpCAM, all of which are present at higher levels in patients than in controls [124, 125]. Beyond simply measuring protein levels to diagnose cancer, it may be possible to exploit changes in their posttranslational modifications. A study based on label-free 
quantitative phosphoproteomics identified several proteins in plasma EVs whose phosphorylation was increased in association with breast cancer, including cGMP-dependent protein kinase 1, nuclear transcription factor, $\mathrm{X}$ box-binding protein 1, Ral GTPase-activating protein subunit alpha-2, and tight junction protein 2 [11].

Pancreatic cancer is a highly malignant tumor. Its early symptoms are not typical and obvious, so early diagnosis is key to a better prognosis. Several miRNAs in serum EVs are upregulated in pancreatic cancer, including miR-17-5p, miR-21, miR-1246, miR-4644, miR-3976, and miR-4306 [126]. Levels of glypican-1, a cell surface proteoglycan, are enriched in exosomes from patients [43, 44], as are levels of serum exosomal proteins CD44v6, Tspan8, EpCAM, MET, and CD104 [127]. Diagnosis may become more specific and sensitive by assaying levels of the proteins GPC1 and CD82 in EVs together with levels of the well-established serum protein carbohydrate antigen 19-9 [128]. Colorectal cancer becomes obviously symptomatic only after it has reached an advanced stage, and its diagnosis depends on colonoscopy. Less invasive methods of early diagnosis may substantially improve prognosis. Seven miRNAs in serum EVs are upregulated in patients and may therefore be useful as biomarkers: let-7a, miR-1229, miR-1246, miR-150, miR-21, miR-223, and miR-23a [129]. At least one protein from serum EVs, CD147, may be useful as a biomarker [130].

Ovarian cancer, the fifth most frequent cancer affecting women, cannot be effectively screened because appropriate biomarkers are lacking. Studies suggest that several EVderived miRNAs may be useful for this purpose, including miR-21, miR-141, miR-200a, miR-200b, miR-200c, miR203, miR-205, and miR-214 [131]. At least one protein derived from plasma EVs, claudin-4, may be useful for diagnosis [132]. Serum-derived EVs from patients with nasopharyngeal carcinoma, a malignancy associated with Epstein-Barr virus (EBV) infection, have been shown to contain EBV components, including latent membrane protein-1 (LMP-1), BamHI-A rightward frame 1 (BARF1), and nucleic acids [133]. Such EV-derived proteins may serve as a more accurate alternative for diagnosis compared with anti-IgA/IgG and anti-VCA tests [134]. Galectin-9 is abundant in nasopharyngeal carcinoma cells infected by EBV, and EVs from the plasma of patients have also been shown to contain galectin9 [135]. Several EBV BART miRNAs, including BART7-3p, BART9-3p, BART17, and especially BART13-3p, are more abundant in exosomes from the serum of patients than in exosomes from the serum of healthy controls [136-138]. In fact, exosomal miR-BART13-3p shows higher diagnostic specificity and sensitivity than traditional methods [136]. Therefore, these EV-derived miRNAs may be useful as a screening tool for diagnosing nasopharyngeal carcinoma.

5.1.2. Blood-Based Liquid Biopsy of Noncancer Diseases. Blood-derived EVs have shown potential for the diagnosis of neurodegenerative diseases, including Alzheimer's disease, amyotrophic lateral sclerosis, Parkinson's disease, and Huntington's disease [139]. The calmodulin-binding protein neurogranin, expressed primarily in the brain, is downregulated in plasma EVs from Alzheimer's patients, and its levels correlate with those of cognitive biomarkers [140]. Identifying reliable biomarkers of Parkinson's disease may be particularly beneficial because treatments exist that can alter the disease and improve prognosis [141]. Levels of $\alpha$-synuclein in plasma EVs are significantly higher in patients with early-stage Parkinson's disease than in healthy controls, and higher levels appear to be associated with a greater risk of progression of motor symptoms [142]. Thus, $\alpha$-synuclein may be a useful diagnostic and prognostic biomarker. Blood-derived EVs have shown potential for the early detection of cardiovascular diseases. Levels of the long noncoding RNA SOCS2-AS1 in plasma EVs are higher in patients with coronary artery disease than in controls, and the RNA itself may help protect against the disease [143]. Levels of miR-1915-3p, miR-4507, and miR-3656 in serum EVs are significantly lower in patients who have suffered acute myocardial infarction than in controls, suggesting that those RNAs may help predict such events, which are a major cause of mortality worldwide [144]. MicroRNAs in EVs may also serve as biomarkers of cardiovascular diseases, such as exosomal miR-183 for predicting myocardial infarction [145].

\subsection{Urine}

5.2.1. Urine-Based Liquid Biopsy of Cancer. Urine can be sampled noninvasively. Its contained EVs have cargoes that may help diagnose prostate cancer and bladder cancer. The disease often does not cause obvious symptoms until later stages, when hematuria or pelvic pain may occur. Screening for the disease relies on a digital rectal exam (DRE) and an assay of prostate-specific antigen (PSA). There is a worldwide consensus that PSA screening for prostate cancer often leads to overdiagnosis, leading researchers to search for better biomarkers [146]. High-throughput mass spectrometry of lipids in urinary EVs identified nine lipid species whose levels differed significantly between patients and controls [65]. These biomarkers may provide diagnostic information. Similarly, proteins from urinary EVs may help diagnose prostate cancer, such as fatty acid-binding protein 5 [147] as well as TGM4, ADSV, Flotilin2, and PARK7 [148, 149]. EVderived RNAs may also aid in the diagnosis, such as miR196a-5p and miR-501-3p [150]. In fact, levels of miRNA miR-2909 in urinary EVs correlate with the severity of prostate cancer [151]. Similarly, blood-derived EVs have also been investigated as noninvasive biomarkers for prostate cancer. Recently, $\mathrm{Li}$ et al. discovered that plasma exosomal miR125a-5p and miR-141-5p performed well as diagnostic biomarkers of prostate cancer [152]. Proteomic analysis of serum exosomes also identified seven proteins present in prostate cancer patients but not in healthy individuals [153]. Further studies that compare the diagnostic accuracy of EVs isolated from blood or urine are still needed.

Bladder cancer is the second most frequent urinary tract cancer, affecting nearly 2 million people globally [154]. As in prostate cancer, the symptoms of bladder cancer are hematuria and pelvic pain, and patients usually become symptomatic when the disease is already in the intermediate or advanced stages. Bladder cancer appears to be associated 
not only with higher levels of urinary EVs [155] but also with higher levels of certain proteins within those EVs, such as alpha-1-antitrypsin and $\mathrm{H} 2 \mathrm{~B} 1 \mathrm{~K}$, whose levels correlate with the grade of urothelial carcinoma [156]. Bladder cancer is also associated with higher levels of the proteins TALDO1, EPS8, and CEAM5 in EVs [157]. Similarly, several RNAs in urinary EVs may have diagnostic usefulness [158]: for example, the panel of long noncoding RNAs MALAT1, PCAT-1, and SPRY4-IT1 showed an area under the receiver operating characteristic curve of 0.813 for diagnosing bladder cancer [159]. A recent study showed that as biomarkers in the detection of bladder cancer, exosomes in serum and urine of patients increased with the invasiveness of tumors [160]. However, diagnostic sensitivity was higher when tumorderived exosomes were isolated from urine than from serum, consistent with the report that urine was a suitable source of EVs for detecting kidney, bladder, and prostate disorders [161]. Another carcinoma that could potentially be diagnosed by EVs isolated from urine is renal cell carcinoma (RCC). In patients with RCC, exosomal proteins such as matrix metalloproteinase 9, ceruloplasmin, podocalyxin, Dickkopf-related protein 4, and carbonic anhydrase IX are upregulated, but AQP1, extracellular matrix metalloproteinase inducer, neprilysin, dipeptidase-1, and syntenin-1n are downregulated [162]. It may be similar to EV-derived miRNAs as biomarkers, such as miR-126-3p, miR-449a, and miR-34b-5p. The combination of miR-126-3p and miR-34b-5p can discriminate patients with small renal masses from healthy individuals, and the combination of miR-126-3p and miR-486-5p can discriminate benign lesions from clear cell RCC [163].

5.2.2. Urine-Based Liquid Biopsy of Noncancer Diseases. Since renal cells release EVs, analysis of urinary EVs may provide insights into the state of the health of the kidney. In fact, levels of the kidney proteins gelatinase and ceruloplasmin in urinary exosomes appear to provide a better index of kidney health in patients with diabetic nephropathy than analysis of total urinary protein, potentially allowing better treatment and management to avoid progression to endstage renal disease $[164,165]$. Levels of the multiligand endocytic receptor C-megalin increase in urinary EVs as diabetic nephropathy progresses [166], while epithelium-specific transcription factor Elf3 is detectable in urinary EVs from patients with diabetic nephropathy but not in EVs from controls [167]. Thus, Elf3 may be a useful marker of irreversible podocyte injury in the early stages of diabetic nephropathy. Another potential marker for the early disease may be Wilm's tumor-1 protein in urinary EVs $[168,169]$, and exosomal levels of the mRNA encoding this protein may correlate with glomerular damage, providing diagnostic and prognostic value [170]. Autoantibody-induced renal damage can lead to lupus nephritis, one of the most common and severe forms of secondary glomerulonephritis. Flare-ups of this disease have been associated with downregulation of the miRNAs let-7a and miR-21 in urinary EVs [171]. Multimarker panels may provide more specific and sensitive diagnoses than single markers: the biomarker panel miR-21, miR-150, and miR-29c can detect early fibrosis formation in lupus nephritis as well as predict disease progression
[172]. Urinary EVs may also be useful for diagnosing Alzheimer's disease: levels of A $\beta 1-42$ and P-S396-tau are higher in patients than in controls [173]. In fact, EVs may contribute to the disease by shuttling toxic amyloid-beta and hyperphosphorylated tau between cells.

\subsection{Saliva}

5.3.1. Saliva-Based Liquid Biopsy of Cancer. As one of the most prevalent cancers worldwide, oral squamous cell carcinoma (OSCC) accounts for around $90 \%$ of oral malignant tumors [174]. Because of its unapparent symptoms at the early stage, patients could easily and unconsciously miss the best diagnostic period; thus, sensitive biomarkers are under urgent demand. Cancer cells can secrete EVs into saliva, and this secretion appears to be related to tumor invasion or metastasis; thus, salivary EVs appear to differ between OSCC patients and healthy individuals, such as in levels of the proteins CD63, CD81, and CD9 [175]. Numerous miRNAs in salivary EVs have also been associated with OSCC, including miR-517b-3p, miR-302b-3p, miR-412-3p, and miR-512-3p [176], as well as miR-24-3p, whose target gene is Period 1 and which gave an area under the receiver operating characteristic curve of 0.738 for diagnosing OSCC [177].

Most strikingly, the studies of salivary EV biomarkers have developed beyond oral cancer. The potential of salivary EVs to detect cancer early may extend to lung cancer. Several studies have reproducibly found various proteins whose levels in salivary EVs differ between lung cancer patients and controls. Sun et al. have been working to explore the utility of salivary EV proteins for lung cancer detection. In 2016, this research group proposed shotgun proteomic analysis illustrating 12 salivary EV proteins that could only be discovered in lung cancer patients [178]. In 2017, they compared salivary and serum exosomal proteomes of lung cancer by LC/MS, and 11 potential proteins were demonstrated in both body fluids, which indicated that both biofluids contain valuable biomarkers [113]. In 2018, they isolated exosomes and microvesicles in human saliva from lung cancer patients and normal subjects. In particular, they identified 5 exosomal proteins and 9 microvesicle proteins, including BPIFA1, CRNN, MUC5B, and IQGAP, as lung-related proteins [179]. Salivary EVs have also been investigated for their diagnostic potential in other cancers. Levels of Melan-A RNA within salivary EVs are upregulated in patients with melanoma [180], while exosomal levels of miR-1246 and miR4644 may have diagnostic potential in pancreatobiliary tract cancers [181]. Levels of several DNA molecules in salivary EVs appear to be upregulated in pancreatic cancer: Apbblip, Daf2, Foxp1, Incenp, Aspn, BC031781, and Gng2 [182]. Similarly, levels of several miRNAs in salivary EVs are upregulated in head and neck squamous cell carcinoma: miR-4865p, miR-10b-5p, and miR-486-3p [183, 184].

5.3.2. Saliva-Based Liquid Biopsy of Noncancer Diseases. Oral lichen planus, a chronic inflammatory disorder of the oral mucosa, can become malignant. Levels of miR-4484 in salivary exosomes may help diagnose this condition [185]. Periodontitis, which causes alveolar bone resorption [186], 
has been associated with elevated exosomal levels of mRNA encoding PD-L1 [187]. Sjögren's syndrome, a common long-term autoimmune disease, has been associated with elevated levels of proteins of saliva EVs involved in innate immunity, cell signaling, and wound repair [188]. The disease has also been associated with upregulation of exosomal levels of guanine nucleotide-binding protein subunit alpha13, adipocyte plasma membrane-associated protein, WD repeat-containing protein 1 , lymphocyte-specific protein 1 , and tyrosine-protein phosphatase nonreceptor type substrate 1 [189]. Inflammatory bowel disease has been linked to altered levels of proteasome subunit alpha type-7 in salivary EVs [190]. Finally, although aging should perhaps not be considered a disease, age-dependent changes in immune and inflammatory responses, as well as apoptosis of salivary gland cells, have been associated with levels of miR-24-3p in salivary EVs [191].

\section{Perspective and Conclusion}

Liquid biopsy has become a hot topic in molecular diagnostics. A growing number of studies have highlighted the potential diagnostic value of EVs. Recently, EVs are considered an attractive liquid biopsy tool as they can sensitively reflect an individual's health status. Although EV-based liquid biopsy has great potential for clinical application, obvious limitations exist. First, different body fluids have different characteristics such as density and viscosity, as well as specific subpopulations of EVs. Hence, EVs isolated from different biofluids may differ in diagnostic accuracy for the same disease. For example, in melanoma patients, lymphatic exudate contains more cancer-derived EVs than plasma, and lymph vessels were shown to be the major route of EV transport from tumors into the circulation $[192,193]$. In lung cancer, tumor-draining pulmonary venous blood contains more cancer-derived EVs than peripheral blood [194]. Further studies are needed to develop standard protocols for sampling different biofluids and isolating EVs from them, as well as for establishing the diagnostic accuracy of those EVs. Second, clinical studies of EV-derived biomarkers typically involve small samples rather than large, longitudinal studies. So large sample trials are needed in the future to establish robust evidence. Third, many EV-derived biomarkers lack specificity, so the same biomarkers can be present in multiple diseases. For example, HER3 is upregulated in breast and lung cancers, while CD24 is abundant in ovarian and breast cancers. Therefore, an accurate diagnosis of a given disease may require detection of the combination of different biomarkers.

In conclusion, this review highlighted the current status of EV-based biomarkers in liquid biopsy and described their biogenesis, contents, and isolation from different biofluids. There is still a long road ahead to the clinical usage of EVbased liquid biopsy, but its potential diagnostic potential still excites and drives scientists to further research on it.

\section{Data Availability}

No data were used to support this study.

\section{Conflicts of Interest}

The authors declare no conflicts of interest.

\section{Acknowledgments}

This work was supported by the National Natural Science Foundation of China (grant nos. 81700941 and 81771048) and by the Science and Technology Department of Sichuan Province (grant nos. 2020YFS0170, 2020YFS0172, and 2020YFS0087).

\section{References}

[1] C. Herrero, A. de la Fuente, C. Casas-Arozamena et al., "Extracellular vesicles-based biomarkers represent a promising liquid biopsy in endometrial cancer," Cancers, vol. 11, 2019.

[2] H. Zheng, X. Wu, J. Yin, S. Wang, Z. Li, and C. You, "Clinical applications of liquid biopsies for early lung cancer detection," American Journal of Cancer Research, vol. 9, pp. 2567-2579, 2019.

[3] R. Hanayama, "Emerging roles of extracellular vesicles in physiology and disease," Journal of Biochemistry, 2020.

[4] A. Emelyanov, T. Shtam, R. Kamyshinsky et al., "Cryo-electron microscopy of extracellular vesicles from cerebrospinal fluid," PLoS One, vol. 15, article e0227949, 2020.

[5] E. Chargaff and R. West, "The biological significance of the thromboplastic protein of blood," The Journal of biological chemistry, vol. 166, pp. 189-197, 1946.

[6] P. Wolf, "The nature and significance of platelet products in human plasma," British Journal of Haematology, vol. 13, pp. 269-288, 1967.

[7] R. E. Veerman, G. Güçlüler Akpinar, M. Eldh, and S. Gabrielsson, "Immune cell-derived extracellular vesicles functions and therapeutic applications," Trends in Molecular Medicine, vol. 25, pp. 382-394, 2019.

[8] G. van Niel, G. D'Angelo, and G. Raposo, "Shedding light on the cell biology of extracellular vesicles," Nature Reviews. Molecular Cell Biology, vol. 19, pp. 213-228, 2018.

[9] W. Liao, Y. Du, C. Zhang et al., "Exosomes: the next generation of endogenous nanomaterials for advanced drug delivery and therapy," Acta Biomaterialia, vol. 86, pp. 1-14, 2019.

[10] K. Al-Nedawi, B. Meehan, J. Micallef et al., "Intercellular transfer of the oncogenic receptor EGFRvIII by microvesicles derived from tumour cells," Nature Cell Biology, vol. 10, pp. 619-624, 2008.

[11] I. H. Chen, L. Xue, C. C. Hsu et al., "Phosphoproteins in extracellular vesicles as candidate markers for breast cancer," Proceedings of the National Academy of Sciences of the United States of America, vol. 114, pp. 3175-3180, 2017.

[12] V. Sokolova, A. K. Ludwig, S. Hornung et al., "Characterisation of exosomes derived from human cells by nanoparticle tracking analysis and scanning electron microscopy," Colloids and Surfaces B: Biointerfaces, vol. 87, pp. 146-150, 2011.

[13] H. Kalra, C. G. Adda, M. Liem et al., "Comparative proteomics evaluation of plasma exosome isolation techniques and assessment of the stability of exosomes in normal human blood plasma," Proteomics, vol. 13, pp. 3354-3364, 2013. 
[14] Y. Jin, K. Chen, Z. Wang et al., "DNA in serum extracellular vesicles is stable under different storage conditions," BMC Cancer, vol. 16, p. 753, 2016.

[15] Q. Ge, Y. Zhou, J. Lu, Y. Bai, X. Xie, and Z. Lu, "miRNA in plasma exosome is stable under different storage conditions," Molecules, vol. 19, pp. 1568-1575, 2014.

[16] Y. Li, Q. Zheng, C. Bao et al., "Circular RNA is enriched and stable in exosomes: a promising biomarker for cancer diagnosis," Cell Research, vol. 25, pp. 981-984, 2015.

[17] R. Kalluri and V. S. LeBleu, "The biology, function, and biomedical applications of exosomes," Science, vol. 367, 2020.

[18] J. K. Jaiswal, N. W. Andrews, and S. M. Simon, "Membrane proximal lysosomes are the major vesicles responsible for calcium-dependent exocytosis in nonsecretory cells," The Journal of cell biology, vol. 159, pp. 625-635, 2002.

[19] A. T. Gatta and J. G. Carlton, "The ESCRT-machinery: closing holes and expanding roles," Current Opinion in Cell Biology, vol. 59, pp. 121-132, 2019.

[20] P. I. Hanson and A. Cashikar, "Multivesicular body morphogenesis," Annual Review of Cell and Developmental Biology, vol. 28, pp. 337-362, 2012.

[21] C. Zhao, G. Zhang, J. Liu, C. Zhang, Y. Yao, and W. Liao, "Exosomal cargoes in OSCC: current findings and potential functions," PeerJ, vol. 8, article e10062, 2020.

[22] N. P. Hessvik and A. Llorente, "Current knowledge on exosome biogenesis and release," Cellular and Molecular Life Sciences: CMLS, vol. 75, pp. 193-208, 2018.

[23] K. Trajkovic, C. Hsu, S. Chiantia et al., "Ceramide triggers budding of exosome vesicles into multivesicular endosomes," Science, vol. 319, pp. 1244-1247, 2008.

[24] A. T. Jan, M. A. Malik, S. Rahman et al., "Perspective insights of exosomes in neurodegenerative diseases: a critical appraisal," Frontiers in Aging Neuroscience, vol. 9, p. 317, 2017.

[25] I. Del Conde, C. N. Shrimpton, P. Thiagarajan, and J. A. López, "Tissue-factor-bearing microvesicles arise from lipid rafts and fuse with activated platelets to initiate coagulation," Blood, vol. 106, pp. 1604-1611, 2005.

[26] O. Morel, L. Jesel, J. M. Freyssinet, and F. Toti, "Cellular mechanisms underlying the formation of circulating microparticles," Arteriosclerosis, Thrombosis, and Vascular Biology, vol. 31, pp. 15-26, 2011.

[27] D. E. Connor, T. Exner, D. D. Ma, and J. E. Joseph, "The majority of circulating platelet-derived microparticles fail to bind annexin $\mathrm{V}$, lack phospholipid-dependent procoagulant activity and demonstrate greater expression of glycoprotein Ib," Thrombosis and Haemostasis, vol. 103, pp. 1044-1052, 2010.

[28] J. Taylor and M. Bebawy, "Proteins regulating microvesicle biogenesis and multidrug resistance in cancer," Proteomics, vol. 19, article e1800165, 2019.

[29] S. L. Latham, C. Chaponnier, V. Dugina, P. O. Couraud, G. E. Grau, and V. Combes, "Cooperation between $\beta$ - and $\gamma$-cytoplasmic actins in the mechanical regulation of endothelial microparticle formation," FASEB journal, vol. 27, pp. 672683, 2013.

[30] B. Li, M. A. Antonyak, J. Zhang, and R. A. Cerione, "RhoA triggers a specific signaling pathway that generates transforming microvesicles in cancer cells," Oncogene, vol. 31, pp. 4740-4749, 2012.
[31] S. Mathivanan and R. J. Simpson, "ExoCarta: a compendium of exosomal proteins and RNA," Proteomics, vol. 9, pp. 49975000, 2009.

[32] D. K. Kim, J. Lee, S. R. Kim et al., "EVpedia: a community web portal for extracellular vesicles research," Bioinformatics, vol. 31, pp. 933-939, 2015.

[33] H. Kalra, R. J. Simpson, H. Ji et al., "Vesiclepedia: a compendium for extracellular vesicles with continuous community annotation," PLoS Biology, vol. 10, article e1001450, 2012.

[34] S. Kreimer, A. M. Belov, I. Ghiran, S. K. Murthy, D. A. Frank, and A. R. Ivanov, "Mass-spectrometry-based molecular characterization of extracellular vesicles: lipidomics and proteomics," Journal of Proteome Research, vol. 14, pp. 2367-2384, 2015.

[35] L. M. Doyle and M. Z. Wang, "Overview of extracellular vesicles, their origin, composition, purpose, and methods for exosome isolation and analysis," Cell, vol. 8, 2019.

[36] Z. Jiang, G. Liu, and J. Li, "Recent progress on the isolation and detection methods of exosomes," Chemistry, an Asian journal, vol. 15, no. 23, pp. 3973-3982, 2020.

[37] K. L. Schey, J. M. Luther, and K. L. Rose, "Proteomics characterization of exosome cargo," Methods, vol. 87, pp. 75-82, 2015.

[38] W. Li, C. Li, T. Zhou et al., "Role of exosomal proteins in cancer diagnosis," Molecular Cancer, vol. 16, p. 145, 2017.

[39] G. Chen, A. C. Huang, W. Zhang et al., "Exosomal PD-L1 contributes to immunosuppression and is associated with anti-PD-1 response," Nature, vol. 560, pp. 382-386, 2018.

[40] C. Li, C. Li, C. Zhi et al., "Clinical significance of PD-L1 expression in serum-derived exosomes in NSCLC patients," Journal of Translational Medicine, vol. 17, p. 355, 2019.

[41] M. N. Theodoraki, S. S. Yerneni, T. K. Hoffmann, W. E. Gooding, and T. L. Whiteside, "Clinical significance of PDL1(+) exosomes in plasma of head and neck cancer patients," Clinical cancer research, vol. 24, pp. 896-905, 2018.

[42] H. Etayash, A. R. McGee, K. Kaur, and T. Thundat, "Nanomechanical sandwich assay for multiple cancer biomarkers in breast cancer cell-derived exosomes," Nanoscale, vol. 8, pp. 15137-15141, 2016.

[43] J. Li, Y. Chen, X. Guo et al., "GPC1 exosome and its regulatory miRNAs are specific markers for the detection and target therapy of colorectal cancer," Journal of Cellular and Molecular Medicine, vol. 21, pp. 838-847, 2017.

[44] S. A. Melo, L. B. Luecke, C. Kahlert et al., "Glypican-1 identifies cancer exosomes and detects early pancreatic cancer," Nature, vol. 523, pp. 177-182, 2015.

[45] P. G. Moon, J. E. Lee, Y. E. Cho et al., "Identification of developmental endothelial locus- 1 on circulating extracellular vesicles as a novel biomarker for early breast cancer detection," Clinical cancer research, vol. 22, pp. 1757-1766, 2016.

[46] B. Costa-Silva, N. M. Aiello, A. J. Ocean et al., "Pancreatic cancer exosomes initiate pre-metastatic niche formation in the liver," Nature Cell Biology, vol. 17, pp. 816-826, 2015.

[47] S. Yokoyama, A. Takeuchi, S. Yamaguchi et al., "Clinical implications of carcinoembryonic antigen distribution in serum exosomal fraction-measurement by ELISA," PLoS One, vol. 12, article e0183337, 2017.

[48] H. Valadi, K. Ekström, A. Bossios, M. Sjöstrand, J. J. Lee, and J. O. Lötvall, "Exosome-mediated transfer of mRNAs and microRNAs is a novel mechanism of genetic exchange between cells," Nature Cell Biology, vol. 9, pp. 654-659, 2007. 
[49] D. Dai, Y. Tan, L. Guo, A. Tang, and Y. Zhao, "Identification of exosomal miRNA biomarkers for diagnosis of papillary thyroid cancer by small RNA sequencing," European Journal of Endocrinology, vol. 182, pp. 111-121, 2020.

[50] Y. Feng, L. L. Lv, W. J. Wu et al., "Urinary exosomes and exosomal CCL2 mRNA as biomarkers of active histologic injury in IgA nephropathy," The American journal of pathology, vol. 188, pp. 2542-2552, 2018.

[51] G. D'Amico, “The commonest glomerulonephritis in the world: IgA nephropathy," The Quarterly journal of medicine, vol. 64, pp. 709-727, 1987.

[52] H. Selvaskandan, C. K. Cheung, M. Muto, and J. Barratt, "New strategies and perspectives on managing IgA nephropathy," Clinical and Experimental Nephrology, vol. 23, pp. 577-588, 2019.

[53] C. Kahlert, S. A. Melo, A. Protopopov et al., "Identification of double-stranded genomic DNA spanning all chromosomes with mutated KRAS and p53 DNA in the serum exosomes of patients with pancreatic cancer," The Journal of biological chemistry, vol. 289, pp. 3869-3875, 2014.

[54] B. K. Thakur, H. Zhang, A. Becker et al., "Double-stranded DNA in exosomes: a novel biomarker in cancer detection," Cell Research, vol. 24, pp. 766-769, 2014.

[55] M. Record, K. Carayon, M. Poirot, and S. Silvente-Poirot, "Exosomes as new vesicular lipid transporters involved in cell-cell communication and various pathophysiologies," Biochimica et biophysica acta, vol. 1841, pp. 108-120, 2014.

[56] W. L. Holland, E. C. Stauter, and B. J. Stith, "Quantification of phosphatidic acid and lysophosphatidic acid by HPLC with evaporative light-scattering detection," The Journal of Lipid Research, vol. 44, pp. 854-858, 2003.

[57] B. J. Stith, J. Hall, P. Ayres, L. Waggoner, J. D. Moore, and W. A. Shaw, "Quantification of major classes of Xenopus phospholipids by high performance liquid chromatography with evaporative light scattering detection," The Journal of Lipid Research, vol. 41, pp. 1448-1454, 2000.

[58] A. Rodriguez-Bernaldo de Quiros, J. López-Hernández, and J. Simal-Lozano, "Separation of phospholipid classes in sea urchin, Paracentrotus lividus by high-performance liquid chromatography," Journal of chromatography B, Analytical technologies in the biomedical and life sciences, vol. 770, pp. 71-75, 2002.

[59] T. Seppänen-Laakso, I. Laakso, H. Vanhanen, K. Kiviranta, T. Lehtimäki, and R. Hiltunen, "Major human plasma lipid classes determined by quantitative high-performance liquid chromatography, their variation and associations with phospholipid fatty acids," Journal of Chromatography B: Biomedical Sciences and Applications, vol. 754, pp. 437445, 2001.

[60] N. U. Olsson, A. J. Harding, C. Harper, and N. Salem Jr., "High-performance liquid chromatography method with light-scattering detection for measurements of lipid class composition: analysis of brains from alcoholics," Journal of Chromatography. B, Biomedical Applications, vol. 681, pp. 213-218, 1996.

[61] L. Tao, J. Zhou, C. Yuan et al., "Metabolomics identifies serum and exosomes metabolite markers of pancreatic cancer," Metabolomics : Official journal of the Metabolomic Society, vol. 15, p. 86, 2019.

[62] X. Luo, M. An, K. C. Cuneo, D. M. Lubman, and L. Li, “Highperformance chemical isotope labeling liquid chromatogra- phy mass spectrometry for exosome metabolomics," Analytical Chemistry, vol. 90, pp. 8314-8319, 2018.

[63] L. Cheng, K. Zhang, Y. Qing et al., "Proteomic and lipidomic analysis of exosomes derived from ovarian cancer cells and ovarian surface epithelial cells," Journal of ovarian research, vol. 13, p. 9, 2020.

[64] T. W. Fan, X. Zhang, C. Wang et al., "Exosomal lipids for classifying early and late stage non-small cell lung cancer," Analytica Chimica Acta, vol. 1037, pp. 256-264, 2018.

[65] T. Skotland, K. Ekroos, D. Kauhanen et al., "Molecular lipid species in urinary exosomes as potential prostate cancer biomarkers," European Journal of Cancer, vol. 70, pp. 122-132, 2017.

[66] D. Vorselen, S. M. van Dommelen, R. Sorkin et al., "The fluid membrane determines mechanics of erythrocyte extracellular vesicles and is softened in hereditary spherocytosis," Nature Communications, vol. 9, p. 4960, 2018.

[67] C. Gardiner, D. D. Vizio, S. Sahoo et al., "Techniques used for the isolation and characterization of extracellular vesicles: results of a worldwide survey," Journal of extracellular vesicles, vol. 5, p. 32945, 2016.

[68] F. A. Scheer, A. D. Michelson, A. L. Frelinger III et al., "The human endogenous circadian system causes greatest platelet activation during the biological morning independent of behaviors," PLoS One, vol. 6, article e24549, 2011.

[69] T. Lange, S. Dimitrov, and J. Born, "Effects of sleep and circadian rhythm on the human immune system," Annals of the New York Academy of Sciences, vol. 1193, pp. 48-59, 2010.

[70] K. W. Witwer, E. I. Buzás, L. T. Bemis et al., "Standardization of sample collection, isolation and analysis methods in extracellular vesicle research," Journal of extracellular vesicles, vol. 2, 2013.

[71] M. D. Lancé, Y. M. Henskens, P. Nelemans et al., "Do blood collection methods influence whole-blood platelet function analysis?," Platelets, vol. 24, pp. 275-281, 2013.

[72] G. Lippi, R. Fontana, P. Avanzini et al., "Influence of mechanical trauma of blood and hemolysis on PFA-100 testing," Blood coagulation \& fibrinolysis, vol. 23, pp. 82-86, 2012.

[73] P. G. Vaughan-Shaw, M. Walker, L. Ooi, N. Gilbert, S. M. Farrington, and M. G. Dunlop, "A simple method to overcome the inhibitory effect of heparin on DNA amplification," Cellular Oncology (Dordrecht), vol. 38, pp. 493-495, 2015.

[74] Y. Yuana, R. M. Bertina, and S. Osanto, "Pre-analytical and analytical issues in the analysis of blood microparticles," Thrombosis and Haemostasis, vol. 105, pp. 396-408, 2011.

[75] F. Granat, A. Geffré, J. P. Braun, and C. Trumel, “Comparison of platelet clumping and complete blood count results with Sysmex XT-2000iV in feline blood sampled on EDTA or EDTA plus CTAD (citrate, theophylline, adenosine and dipyridamole)," Journal of Feline Medicine and Surgery, vol. 13, pp. 953-958, 2011.

[76] R. Lacroix, C. Judicone, P. Poncelet et al., "Impact of preanalytical parameters on the measurement of circulating microparticles: towards standardization of protocol," Journal of thrombosis and haemostasis : JTH, vol. 10, pp. 437-446, 2012.

[77] Z. Wang, S. Hill, J. M. Luther, D. L. Hachey, and K. L. Schey, "Proteomic analysis of urine exosomes by multidimensional protein identification technology (MudPIT)," Proteomics, vol. 12, pp. 329-338, 2012. 
[78] S. Park, K. Lee, I. B. Park et al., "The profiles of microRNAs from urinary extracellular vesicles (EVs) prepared by various isolation methods and their correlation with serum EV microRNAs," Diabetes Research and Clinical Practice, vol. 160, p. 108010, 2020.

[79] X. Xu, K. Barreiro, L. Musante et al., "Management of TammHorsfall protein for reliable urinary analytics," Proteomics Clinical Applications, vol. 13, article e1900018, 2019.

[80] P. Fernández-Llama, S. Khositseth, P. A. Gonzales, R. A. Star, T. Pisitkun, and M. A. Knepper, "Tamm-Horsfall protein and urinary exosome isolation," Kidney International, vol. 77, pp. 736-742, 2010.

[81] L. Musante, M. Saraswat, E. Duriez et al., "Biochemical and physical characterisation of urinary nanovesicles following CHAPS treatment," PLoS One, vol. 7, article e37279, 2012.

[82] M. Puhka, M. E. Nordberg, S. Valkonen et al., "KeepEX, a simple dilution protocol for improving extracellular vesicle yields from urine," European journal of pharmaceutical sciences, vol. 98, pp. 30-39, 2017.

[83] K. R. Bhattarai, H. R. Kim, and H. J. Chae, "Compliance with saliva collection protocol in healthy volunteers: strategies for managing risk and errors," International Journal of Medical Sciences, vol. 15, pp. 823-831, 2018.

[84] S. Nishide, T. Yoshihara, H. Hongou, T. Kanehira, and Y. Yawaka, "Daily life habits associated with eveningness lead to a higher prevalence of dental caries in children," Journal of dental sciences, vol. 14, pp. 302-308, 2019.

[85] C. Golatowski, M. G. Salazar, V. M. Dhople et al., "Comparative evaluation of saliva collection methods for proteome analysis," Clinica chimica acta; international journal of clinical chemistry, vol. 419, pp. 42-46, 2013.

[86] S. K. Putnam, C. Lopata, J. D. Fox et al., "Comparison of saliva collection methods in children with high-functioning autism spectrum disorders: acceptability and recovery of cortisol," Child Psychiatry and Human Development, vol. 43, pp. 560-573, 2012.

[87] P. Han and S. Ivanovski, "Effect of saliva collection methods on the detection of periodontium-related genetic and epigenetic biomarkers-a pilot study," International Journal of Molecular Sciences, vol. 20, 2019.

[88] L. N. van der Vorm, J. Brouwers, C. Mondria, B. de Laat, P. G. de Groot, and J. A. Remijn, "Salivary tissue factor induces thrombin generation in a diurnal rhythm," Research and practice in thrombosis and haemostasis, vol. 2, pp. 757-761, 2018.

[89] C. Tzortzi, P. Proff, M. Redlich et al., "Cortisol daily rhythm in saliva of healthy school children," International Dental Journal, vol. 59, pp. 12-18, 2009.

[90] M. Gonzalez-Begne, B. Lu, X. Han et al., "Proteomic analysis of human parotid gland exosomes by multidimensional protein identification technology (MudPIT)," Journal of Proteome Research, vol. 8, pp. 1304-1314, 2009.

[91] N. Rohleder and U. M. Nater, "Determinants of salivary alpha-amylase in humans and methodological considerations," Psychoneuroendocrinology, vol. 34, pp. 469-485, 2009.

[92] D. Yang, W. Zhang, H. Zhang et al., "Progress, opportunity, and perspective on exosome isolation - efforts for efficient exosome-based theranostics," Theranostics, vol. 10, pp. 3684-3707, 2020.

[93] B. Pang, Y. Zhu, J. Ni et al., "Extracellular vesicles: the next generation of biomarkers for liquid biopsy-based prostate cancer diagnosis," Theranostics, vol. 10, pp. 2309-2326, 2020.
[94] M. A. Livshits, E. Khomyakova, E. G. Evtushenko et al., "Isolation of exosomes by differential centrifugation: theoretical analysis of a commonly used protocol," Scientific Reports, vol. 5, p. 17319, 2015.

[95] B. J. Tauro, D. W. Greening, R. A. Mathias et al., "Comparison of ultracentrifugation, density gradient separation, and immunoaffinity capture methods for isolating human colon cancer cell line LIM1863-derived exosomes," Methods, vol. 56, pp. 293-304, 2012.

[96] N. G. Anderson, "An introduction to particle separations in zonal centrifuges," National Cancer Institute Monograph, vol. 21, pp. 9-39, 1966.

[97] P. Li, M. Kaslan, S. H. Lee, J. Yao, and Z. Gao, "Progress in exosome isolation techniques," Theranostics, vol. 7, pp. 789-804, 2017.

[98] A. Cheruvanky, H. Zhou, T. Pisitkun et al., "Rapid isolation of urinary exosomal biomarkers using a nanomembrane ultrafiltration concentrator," American Journal of Physiology - Renal Physiology, vol. 292, pp. F1657-F1661, 2007.

[99] S. Busatto, G. Vilanilam, T. Ticer et al., "Tangential flow filtration for highly efficient concentration of extracellular vesicles from large volumes of fluid," Cell, vol. 7, 2018.

[100] M. Zhang, K. Jin, L. Gao et al., "Methods and technologies for exosome isolation and characterization," Small Methods, vol. 2, p. 1800021, 2018.

[101] K. Sidhom, P. O. Obi, and A. Saleem, "A review of exosomal isolation methods: is size exclusion chromatography the best option?," International Journal of Molecular Sciences, vol. 21, 2020.

[102] P. Sharma, S. Ludwig, L. Muller et al., "Immunoaffinity-based isolation of melanoma cell-derived exosomes from plasma of patients with melanoma," Journal of extracellular vesicles, vol. 7, p. 1435138, 2018.

[103] Y. T. Kang, E. Purcell, C. Palacios-Rolston et al., "Isolation and profiling of circulating tumor-associated exosomes using extracellular vesicular lipid-protein binding affinity based microfluidic device," Small, vol. 15, article e1903600, 2019.

[104] N. Zarovni, A. Corrado, P. Guazzi et al., "Integrated isolation and quantitative analysis of exosome shuttled proteins and nucleic acids using immunocapture approaches," Methods, vol. 87, pp. 46-58, 2015.

[105] G. K. Patel, M. A. Khan, H. Zubair, S. K. Srivastava, S. Singh, and A. P. Singh, "Comparative analysis of exosome isolation methods using culture supernatant for optimum yield, purity and downstream applications," Scientific Reports, vol. 9, p. $5335,2019$.

[106] S. L. Sim, T. He, A. Tscheliessnig, M. Mueller, R. B. Tan, and A. Jungbauer, "Protein precipitation by polyethylene glycol: a generalized model based on hydrodynamic radius," Journal of Biotechnology, vol. 157, pp. 315-319, 2012.

[107] T. Kimura, B. Ferran, Y. Tsukahara et al., "Production of adeno-associated virus vectors for in vitro and in vivo applications," Scientific Reports, vol. 9, p. 13601, 2019.

[108] F. Yang, X. Liao, Y. Tian, and G. Li, "Exosome separation using microfluidic systems: size-based, immunoaffinitybased and dynamic methodologies," Biotechnology Journal, vol. 12, 2017.

[109] J. Lu, J. Pang, Y. Chen et al., “Application of microfluidic chips in separation and analysis of extracellular vesicles in liquid biopsy for cancer," Micromachines, vol. 10, 2019. 
[110] D. Kwapisz, "The first liquid biopsy test approved. Is it a new era of mutation testing for non-small cell lung cancer?," Annals of translational medicine, vol. 5, p. 46, 2017.

[111] S. Saejong, N. Townamchai, P. Somparn et al., "MicroRNA21 in plasma exosome, but not from whole plasma, as a biomarker for the severe interstitial fibrosis and tubular atrophy (IF/TA) in post-renal transplantation," Asian Pacific Journal of Allergy and Immunology, 2020.

[112] A. Lapitz, A. Arbelaiz, C. J. O'Rourke et al., "Patients with cholangiocarcinoma present specific RNA profiles in serum and urine extracellular vesicles mirroring the tumor expression: novel liquid biopsy biomarkers for disease diagnosis," Cell, vol. 9, 2020.

[113] Y. Sun, S. Liu, Z. Qiao et al., "Systematic comparison of exosomal proteomes from human saliva and serum for the detection of lung cancer," Analytica Chimica Acta, vol. 982, pp. 84-95, 2017.

[114] P. Goldstraw, D. Ball, J. R. Jett et al., "Non-small-cell lung cancer," Lancet, vol. 378, pp. 1727-1740, 2011.

[115] A. Srivastava, N. Amreddy, M. Razaq et al., "Exosomes as theranostics for lung cancer," Advances in Cancer Research, vol. 139, pp. 1-33, 2018.

[116] T. An, S. Qin, D. Sun et al., "Unique protein profiles of extracellular vesicles as diagnostic biomarkers for early and advanced non-small cell lung cancer," Proteomics, vol. 19, article e1800160, 2019.

[117] L. Niu, X. Song, N. Wang, L. Xue, X. Song, and L. Xie, "Tumor-derived exosomal proteins as diagnostic biomarkers in non-small cell lung cancer," Cancer Science, vol. 110, pp. 433-442, 2019.

[118] C. Li, Y. Lv, C. Shao et al., "Tumor-derived exosomal lncRNA GAS5 as a biomarker for early-stage non-small-cell lung cancer diagnosis," Journal of Cellular Physiology, vol. 234, pp. 20721-20727, 2019.

[119] Y. Zhang, Y. Zhang, Y. Yin, and S. Li, "Detection of circulating exosomal miR-17-5p serves as a novel non-invasive diagnostic marker for non-small cell lung cancer patients," Pathology, research and practice, vol. 215, article 152466, 2019.

[120] F. Kamangar, G. M. Dores, and W. F. Anderson, "Patterns of cancer incidence, mortality, and prevalence across five continents: defining priorities to reduce cancer disparities in different geographic regions of the world," Journal of clinical oncology, vol. 24, pp. 2137-2150, 2006.

[121] T. Fiskaa, E. Knutsen, M. A. Nikolaisen et al., "Distinct small RNA signatures in extracellular vesicles derived from breast cancer cell lines," PLoS One, vol. 11, article e0161824, 2016.

[122] B. N. Hannafon, Y. D. Trigoso, C. L. Calloway et al., "Plasma exosome microRNAs are indicative of breast cancer," Breast cancer research, vol. 18, p. 90, 2016.

[123] M. Yoshikawa, H. Iinuma, Y. Umemoto, T. Yanagisawa, A. Matsumoto, and H. Jinno, "Exosome-encapsulated microRNA-223-3p as a minimally invasive biomarker for the early detection of invasive breast cancer," Oncology Letters, vol. 15, pp. 9584-9592, 2018.

[124] M. Wang, S. Ji, G. Shao et al., "Effect of exosome biomarkers for diagnosis and prognosis of breast cancer patients," Clinical \& translational oncology, vol. 20, pp. 906-911, 2018.

[125] S. Fang, H. Tian, X. Li et al., "Clinical application of a microfluidic chip for immunocapture and quantification of circulating exosomes to assist breast cancer diagnosis and molecular classification," PLoS One, vol. 12, article e0175050, 2017.

[126] R. Que, G. Ding, J. Chen, and L. Cao, “Analysis of serum exosomal microRNAs and clinicopathologic features of patients with pancreatic adenocarcinoma," World Journal of Surgical Oncology, vol. 11, p. 219, 2013.

[127] B. Madhavan, S. Yue, U. Galli et al., "Combined evaluation of a panel of protein and miRNA serum-exosome biomarkers for pancreatic cancer diagnosis increases sensitivity and specificity," International Journal of Cancer, vol. 136, pp. 26162627, 2015.

[128] D. Xiao, Z. Dong, L. Zhen et al., "Combined exosomal GPC1, CD82, and serum CA19-9 as multiplex targets: a specific, sensitive, and reproducible detection panel for the diagnosis of pancreatic cancer," Molecular cancer research, vol. 18, pp. 300-310, 2020.

[129] H. Ogata-Kawata, M. Izumiya, D. Kurioka et al., "Circulating exosomal microRNAs as biomarkers of colon cancer," PLoS One, vol. 9, article e92921, 2014.

[130] Y. Yoshioka, N. Kosaka, Y. Konishi et al., "Ultra-sensitive liquid biopsy of circulating extracellular vesicles using ExoScreen," Nature Communications, vol. 5, p. 3591, 2014.

[131] D. D. Taylor and C. Gercel-Taylor, "MicroRNA signatures of tumor-derived exosomes as diagnostic biomarkers of ovarian cancer," Gynecologic Oncology, vol. 110, pp. 1321, 2008.

[132] J. Li, C. A. Sherman-Baust, M. Tsai-Turton, R. E. Bristow, R. B. Roden, and P. J. Morin, "Claudin-containing exosomes in the peripheral circulation of women with ovarian cancer," BMC Cancer, vol. 9, p. 244, 2009.

[133] M. A. H. AbuSalah, S. H. Gan, M. A. I. Al-Hatamleh, A. A. Irekeola, R. H. Shueb, and C. Y. Yean, "Recent advances in diagnostic approaches for Epstein-Barr virus," Pathogens, vol. 9, 2020.

[134] K. Houali, X. Wang, Y. Shimizu et al., "A new diagnostic marker for secreted Epstein-Barr virus encoded LMP1 and BARF1 oncoproteins in the serum and saliva of patients with nasopharyngeal carcinoma," Clinical cancer research, vol. 13, pp. 4993-5000, 2007.

[135] J. Klibi, T. Niki, A. Riedel et al., "Blood diffusion and Th1suppressive effects of galectin-9-containing exosomes released by Epstein-Barr virus-infected nasopharyngeal carcinoma cells," Blood, vol. 113, pp. 1957-1966, 2009.

[136] M. Zhao, A. Nanbo, L. Sun, and Z. Lin, "Extracellular vesicles in Epstein-Barr virus' life cycle and pathogenesis," Microorganisms, vol. 7, 2019.

[137] O. Ramayanti, S. A. Verkuijlen, P. Novianti et al., "Vesiclebound EBV-BART13-3p miRNA in circulation distinguishes nasopharyngeal from other head and neck cancer and asymptomatic EBV-infections," International Journal of Cancer, vol. 144, pp. 2555-2566, 2019.

[138] C. Gourzones, F. R. Ferrand, C. Amiel et al., "Consistent high concentration of the viral microRNA BART17 in plasma samples from nasopharyngeal carcinoma patients-evidence of non-exosomal transport," Virology Journal, vol. 10, p. $119,2013$.

[139] L. Wang and L. Zhang, "Circulating exosomal miRNA as diagnostic biomarkers of neurodegenerative diseases," Frontiers in Molecular Neuroscience, vol. 13, p. 53, 2020.

[140] W. Liu, H. Lin, X. He et al., "Neurogranin as a cognitive biomarker in cerebrospinal fluid and blood exosomes for 
Alzheimer's disease and mild cognitive impairment," Translational Psychiatry, vol. 10, p. 125, 2020.

[141] J. D. Elsworth, "Parkinson's disease treatment: past, present, and future," Journal of neural transmission, vol. 127, pp. 785-791, 2020.

[142] M. Niu, Y. Li, G. Li et al., "A longitudinal study on $\alpha$-synuclein in plasma neuronal exosomes as a biomarker for Parkinson's disease development and progression," European Journal of Neurology, vol. 27, pp. 967-974, 2020.

[143] C. Liang, L. Zhang, X. Lian, T. Zhu, Y. Zhang, and N. Gu, "Circulating exosomal SOCS2-AS1 acts as a novel biomarker in predicting the diagnosis of coronary artery disease," BioMed Research International, vol. 2020, Article ID 9182091, 10 pages, 2020.

[144] J. Su, J. Li, Q. Yu et al., "Exosomal miRNAs as potential biomarkers for acute myocardial infarction," IUBMB Life, vol. 72, pp. 384-400, 2020.

[145] X. Zhao, Y. Jia, H. Chen, H. Yao, and W. Guo, "Plasmaderived exosomal miR-183 associates with protein kinase activity and may serve as a novel predictive biomarker of myocardial ischemic injury," Experimental and Therapeutic Medicine, vol. 18, pp. 179-187, 2019.

[146] A. R. Alberts, I. G. Schoots, and M. J. Roobol, "Prostatespecific antigen-based prostate cancer screening: past and future," International Journal of Urology, vol. 22, pp. 524$532,2015$.

[147] K. Fujita, H. Kume, K. Matsuzaki et al., "Proteomic analysis of urinary extracellular vesicles from high Gleason score prostate cancer," Scientific Reports, vol. 7, p. 42961, 2017.

[148] T. Sequeiros, M. Rigau, C. Chiva et al., "Targeted proteomics in urinary extracellular vesicles identifies biomarkers for diagnosis and prognosis of prostate cancer," Oncotarget, vol. 8, pp. 4960-4976, 2017.

[149] L. Wang, T. Skotland, V. Berge, K. Sandvig, and A. Llorente, "Exosomal proteins as prostate cancer biomarkers in urine: from mass spectrometry discovery to immunoassay-based validation," European journal of pharmaceutical sciences, vol. 98, pp. 80-85, 2017.

[150] M. Rodríguez, C. Bajo-Santos, N. P. Hessvik et al., "Identification of non-invasive miRNAs biomarkers for prostate cancer by deep sequencing analysis of urinary exosomes," Molecular Cancer, vol. 16, 2017.

[151] S. Wani, D. Kaul, R. S. Mavuduru, N. Kakkar, and A. Bhatia, "Urinary-exosomal miR-2909: a novel pathognomonic trait of prostate cancer severity," Journal of Biotechnology, vol. 259, pp. 135-139, 2017.

[152] W. Li, Y. Dong, K. J. Wang, Z. Deng, W. Zhang, and H. F. Shen, "Plasma exosomal miR-125a-5p and miR-141-5p as non-invasive biomarkers for prostate cancer," Neoplasma, vol. 67, no. 6, pp. 1314-1318, 2020.

[153] G. K. Panigrahi, P. P. Praharaj, H. Kittaka et al., "Exosome proteomic analyses identify inflammatory phenotype and novel biomarkers in African American prostate cancer patients," Cancer Medicine, vol. 8, pp. 1110-1123, 2019.

[154] R. L. Siegel, K. D. Miller, and A. Jemal, "Cancer statistics, 2016," CA: a Cancer Journal for Clinicians, vol. 66, pp. 7-30, 2016.

[155] L. G. Liang, M. Q. Kong, S. Zhou et al., "An integrated double-filtration microfluidic device for isolation, enrichment and quantification of urinary extracellular vesicles for detection of bladder cancer," Scientific Reports, vol. 7, Article ID 46224, 2017.
[156] S. Y. Lin, C. H. Chang, H. C. Wu et al., "Proteome profiling of urinary exosomes identifies alpha 1-antitrypsin and H2B1K as diagnostic and prognostic biomarkers for urothelial carcinoma," Scientific Reports, vol. 6, p. 34446, 2016.

[157] C. R. Silvers, H. Miyamoto, E. M. Messing, G. J. Netto, and Y. F. Lee, "Characterization of urinary extracellular vesicle proteins in muscle-invasive bladder cancer," Oncotarget, vol. 8, pp. 91199-91208, 2017.

[158] J. Lee, M. K. KQ, A. J. Pavlopoulos et al., "Altered proteome of extracellular vesicles derived from bladder cancer patients urine," Molecules and Cells, vol. 41, pp. 179-187, 2018.

[159] Y. Zhan, L. Du, L. Wang et al., "Expression signatures of exosomal long non-coding RNAs in urine serve as novel non-invasive biomarkers for diagnosis and recurrence prediction of bladder cancer," Molecular Cancer, vol. 17, 2018.

[160] F. Elsharkawi, M. Elsabah, M. Shabayek, and H. Khaled, "Urine and serum exosomes as novel biomarkers in detection of bladder cancer," Asian Pacific Journal of Cancer Prevention : APJCP, vol. 20, pp. 2219-2224, 2019.

[161] F. Royo, P. Zuñiga-Garcia, P. Sanchez-Mosquera et al., "Different EV enrichment methods suitable for clinical settings yield different subpopulations of urinary extracellular vesicles from human samples," Journal of extracellular vesicles, vol. 5, p. 29497, 2016.

[162] F. Raimondo, L. Morosi, S. Corbetta et al., "Differential protein profiling of renal cell carcinoma urinary exosomes," Molecular BioSystems, vol. 9, pp. 1220-1233, 2013.

[163] H. Butz, R. Nofech-Mozes, Q. Ding et al., "Exosomal microRNAs are diagnostic biomarkers and can mediate cell-cell communication in renal cell carcinoma," European Urology Focus, vol. 2, pp. 210-218, 2016.

[164] V. Soetikno, W. Arozal, M. Louisa, and R. Setiabudy, "New insight into the molecular drug target of diabetic nephropathy," International Journal of Endocrinology, vol. 2014, Article ID 968681, 9 pages, 2014.

[165] K. P. Gudehithlu, I. Garcia-Gomez, J. Vernik et al., "In diabetic kidney disease urinary exosomes better represent kidney specific protein alterations than whole urine," American Journal of Nephrology, vol. 42, pp. 418-424, 2015.

[166] S. De, S. Kuwahara, M. Hosojima et al., "Exocytosis-mediated urinary full-length megalin excretion is linked with the pathogenesis of diabetic nephropathy," Diabetes, vol. 66, pp. 1391-1404, 2017.

[167] A. Sakurai, H. Ono, A. Ochi et al., "Involvement of Elf3 on Smad3 activation-dependent injuries in podocytes and excretion of urinary exosome in diabetic nephropathy," PLoS One, vol. 14, article e0216788, 2019.

[168] H. Zhou, H. Kajiyama, T. Tsuji et al., "Urinary exosomal Wilms' tumor-1 as a potential biomarker for podocyte injury," American Journal of Physiology - Renal Physiology, vol. 305, pp. F553-F559, 2013.

[169] A. Kalani, A. Mohan, M. M. Godbole et al., "Wilm's tumor-1 protein levels in urinary exosomes from diabetic patients with or without proteinuria," PLoS One, vol. 8, article e60177, 2013.

[170] H. Abe, A. Sakurai, H. Ono et al., "Urinary exosomal mRNA of WT1 as diagnostic and prognostic biomarker for diabetic nephropathy," The journal of medical investigation, vol. 65, pp. 208-215, 2018. 
[171] P. Tangtanatakul, S. Klinchanhom, P. Sodsai et al., "Downregulation of let-7a and $\mathrm{miR}-21$ in urine exosomes from lupus nephritis patients during disease flare," Asian Pacific Journal of Allergy and Immunology, vol. 37, pp. 189-197, 2019.

[172] C. Solé, T. Moliné, M. Vidal, J. Ordi-Ros, and J. CortésHernández, "An exosomal urinary miRNA signature for early diagnosis of renal fibrosis in lupus nephritis," Cell, vol. 8, 2019.

[173] R. Sun, H. Wang, Y. Shi et al., "A pilot study of urinary exosomes in Alzheimer's disease," Neuro-Degenerative Diseases, vol. 19, pp. 184-191, 2019.

[174] F. Bray, J. Ferlay, I. Soerjomataram, R. L. Siegel, L. A. Torre, and A. Jemal, "Global cancer statistics 2018: GLOBOCAN estimates of incidence and mortality worldwide for 36 cancers in 185 countries," CA: a Cancer Journal for Clinicians, vol. 68, pp. 394-424, 2018.

[175] A. Zlotogorski-Hurvitz, D. Dayan, G. Chaushu, T. Salo, and M. Vered, "Morphological and molecular features of oral fluid-derived exosomes: oral cancer patients versus healthy individuals," Journal of Cancer Research and Clinical Oncology, vol. 142, pp. 101-110, 2015.

[176] C. Gai, F. Camussi, R. Broccoletti et al., "Salivary extracellular vesicle-associated miRNAs as potential biomarkers in oral squamous cell carcinoma," BMC Cancer, vol. 18, 2018.

[177] L. He, F. Ping, Z. Fan et al., "Salivary exosomal miR-24-3p serves as a potential detective biomarker for oral squamous cell carcinoma screening," Biomedicine and Pharmacotherapy, vol. 121, 2020.

[178] Y. Sun, Z. Xia, Z. Shang et al., "Facile preparation of salivary extracellular vesicles for cancer proteomics," Scientific Reports, vol. 6, p. 24669, 2016.

[179] Y. Sun, C. Huo, Z. Qiao et al., "Comparative proteomic analysis of exosomes and microvesicles in human saliva for lung cancer," Journal of Proteome Research, vol. 17, pp. 11011107, 2018.

[180] J. Kim, H. Shin, and J. Park, "RNA in salivary extracellular vesicles as a possible tool for systemic disease diagnosis," Journal of Dental Research, vol. 96, pp. 938-944, 2017.

[181] T. Machida, T. Tomofuji, T. Maruyama et al., "miR-1246 and miR-4644 in salivary exosome as potential biomarkers for pancreatobiliary tract cancer," Oncology Reports, vol. 36, pp. 2375-2381, 2016.

[182] C. Lau, Y. Kim, D. Chia et al., "Role of pancreatic cancerderived exosomes in salivary biomarker development," The Journal of biological chemistry, vol. 288, pp. 26888-26897, 2013.

[183] S. Principe, A. B. Hui, J. Bruce, A. Sinha, F. F. Liu, and T. Kislinger, "Tumor-derived exosomes and microvesicles in head and neck cancer: implications for tumor biology and biomarker discovery," Proteomics, vol. 13, pp. 16081623, 2013.

[184] S. Langevin, D. Kuhnell, T. Parry et al., "Comprehensive microRNA-sequencing of exosomes derived from head and neck carcinoma cells in vitro reveals common secretion profiles and potential utility as salivary biomarkers," Oncotarget, vol. 8, pp. 82459-82474, 2017.

[185] J. S. Byun, S. H. Hong, J. K. Choi, J. K. Jung, and H. J. Lee, "Diagnostic profiling of salivary exosomal microRNAs in oral lichen planus patients," Oral Diseases, vol. 21, pp. 987-993, 2015.
[186] W. Wisitrasameewong, M. Kajiya, A. Movila et al., "DCSTAMP is an osteoclast fusogen engaged in periodontal bone resorption," Journal of Dental Research, vol. 96, pp. 685-693, 2017.

[187] J. Yu, Y. Lin, X. Xiong et al., "Detection of exosomal PD-L1 RNA in saliva of patients with periodontitis," Frontiers in Genetics, vol. 10, p. 202, 2019.

[188] L. A. Aqrawi, H. K. Galtung, B. Vestad et al., "Identification of potential saliva and tear biomarkers in primary Sjögren's syndrome, utilising the extraction of extracellular vesicles and proteomics analysis," Arthritis Research and Therapy, vol. 19, p. 14, 2017.

[189] L. A. Aqrawi, H. K. Galtung, B. Vestad et al., "Identification of potential saliva and tear biomarkers in primary Sjogren's syndrome, utilising the extraction of extracellular vesicles and proteomics analysis," Arthritis Research \& Therapy, vol. 19, p. 14, 2017.

[190] X. Zheng, F. Chen, Q. Zhang et al., "Salivary exosomal PSMA7: a promising biomarker of inflammatory bowel disease," Protein \& Cell, vol. 8, pp. 686-695, 2017.

[191] T. Machida, T. Tomofuji, D. Ekuni et al., "MicroRNAs in salivary exosome as potential biomarkers of aging," International Journal of Molecular Sciences, vol. 16, pp. 2129421309, 2015.

[192] M. A. Broggi, L. Maillat, C. C. Clement et al., "Tumor-associated factors are enriched in lymphatic exudate compared to plasma in metastatic melanoma patients," The Journal of experimental medicine, vol. 216, pp. 1091-1107, 2019.

[193] S. García-Silva, A. Benito-Martín, S. Sánchez-Redondo et al., "Use of extracellular vesicles from lymphatic drainage as surrogate markers of melanoma progression and BRAF (V600E) mutation," The Journal of experimental medicine, vol. 216, pp. 1061-1070, 2019.

[194] A. Navarro, L. Molins, R. M. Marrades et al., "Exosome analysis in tumor-draining pulmonary vein identifies NSCLC patients with higher risk of relapse after curative surgery," Cancers, vol. 11, 2019.

[195] H. Kim, D. W. Kim, and J. Y. Cho, "Exploring the key communicator role of exosomes in cancer microenvironment through proteomics," Proteome Science, vol. 17, p. 5, 2019.

[196] S. Ailawadi, X. Wang, H. Gu, and G. C. Fan, "Pathologic function and therapeutic potential of exosomes in cardiovascular disease," Biochimica et biophysica acta, vol. 1852, pp. 111, 2015. 